\title{
Energy performance certification in mechanical manufacturing industry: A review and analysis
}

\author{
Wei Cai a , Conghu Liu b, ${ }^{*}$, Kee-hung Laic, Li Li a , Jorge Cunha ${ }^{\mathrm{e}}$, Luoke Hu ${ }^{\mathrm{f}}$ \\ a. College of Engineering and Technology, Southwest University, Chongqing, 400715, China. \\ b. Sino-US Global Logistics Institute, Shanghai Jiao Tong University, Shanghai, 200030, China. \\ c. Department of Logistics and Maritime Studies, Faculty of Business, The Hong Kong Polytechnic University, Hung Hum, \\ Kowloon, Hong Kong \\ d. School of Mechanical and Electronic Engineering, Suzhou University, Suzhou 234000, China \\ e. ALGORITMI Centre, School of Engineering, University of Minho, Campus Azurém, 4800-058 Guimarães, Portugal \\ f. Faculty of Business Administration, University of Macau, Macau, China
}

\begin{abstract}
:
The energy performance certification has been recognized as an effective assessment methodology and tool to systematically manage energy consumption and improve energy performance. In the process manufacturing industry and building industry, a large number of energy performance certifications have been applied worldwide with remarkable results achieved in energy saving and emissions mitigation. Mechanical manufacturing industry, which is characterised as a typical discrete manufacturing having wide distribution in operations with large consumption of energy and low efficiency, has considerable potential of benefiting from energy saving and emissions mitigation. The objective of this paper is to perform a review and analysis of energy performance certification in mechanical manufacturing industry for evaluating its potentials and applicability for performance enhancement. We begin with analyzing energy performance certification and research gaps to develop an operational definition of energy performance certification. The scope of energy performance certification and the method for data acquisition are reviewed. Next, we establish the classification of energy performance certification from perspectives of the energy benchmarking, rating and labelling to lay a foundation for its implementation framework and evaluating its practicability. Through the systemic review and analysis, the current state of researching energy performance certification is provided with the methods for developing energy performance certification summarized and analyzed. These findings are useful references for managers to strengthen energy management and monitoring and improve energy performance in mechanical manufacturing industry.
\end{abstract}

\footnotetext{
* Corresponding authors

Sino-US Global Logistics Institute, Shanghai Jiao Tong University, Shanghai, 200030, China.

E-mail addresses: weicai@swu.edu.cn (W. Cai); lch339@126.com (C. Liu)
} 
Keywords: Energy performance, Certification; Energy benchmarking, Energy rating, Energy labelling; Mechanical manufacturing industry

\section{Introduction}

\subsection{Energy consumption in industry}

In view of natural resource consumption and environmental degradation [1,2], developing low carbon operations is an important part of national sustainability strategy $[3,4,5]$. The International Energy Agency (IEA) investigation showed that the global total final energy consumption experienced a rapid upward trend from 2000 to 2016 as shown in Fig.1. The global total final energy consumption was 791 Mtoe in 2000, and the global total final energy consumption was 1978 Mtoe in 2016 recording an increase of 60\%. The share of industry energy consumption increased by 692 Mtoe in 2016 compared with that in year 2000 [6]. With industrialization progresses, the share of industry energy consumption has been driving a great change of world energy structure and an incredible growth in $\mathrm{CO}_{2}$ emissions $[7,8]$.

Mechanical manufacturing is a pillar industry supporting national economy. Yet, it brings vast amounts of natural resource consumption at low energy efficiency $[9,10]$ with serious environmental pollution resulted in the transformation process from manufacturing resources to products $[11,12]$. Energy consumption of mechanical manufacturing industry is responsible for $74.7 \%$ of the total energy consumption in manufacturing industry [13]. Plentiful studies show that energy efficiency is fairly low in mechanical manufacturing, usually less than $30 \%$ [14]. With wide distribution and great energy consumption in low efficiency, mechanical manufacturing industry has considerable energy-saving potential.

There are effective measures of energy saving and $\mathrm{CO}_{2}$ mitigation in production proposed $[15,16]$ and that efforts have been made for green and sustainable processes [17]. Some policies targeting to promote sustainable development have been implemented to bring greener shifts of manufacturing sectors [18]. 


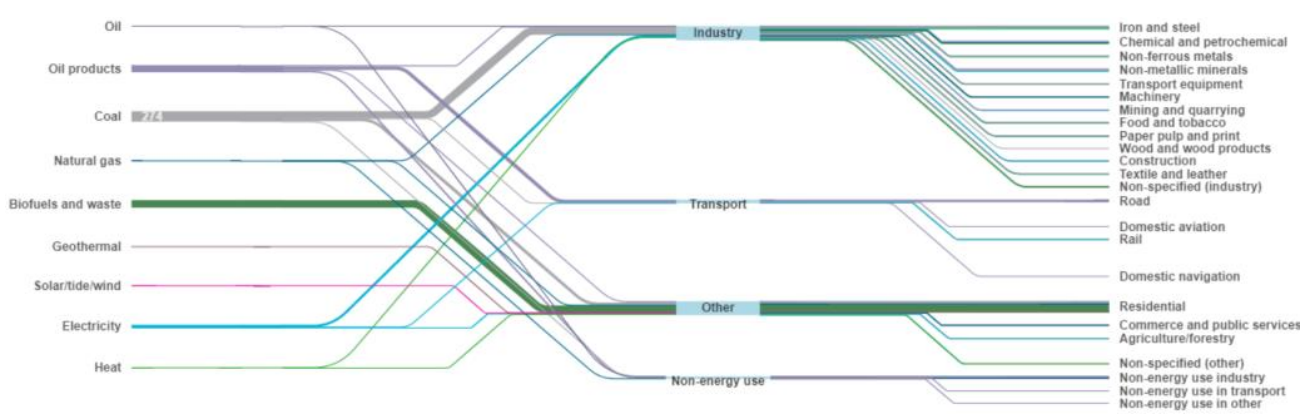

(a) Total final energy consumption in 2000
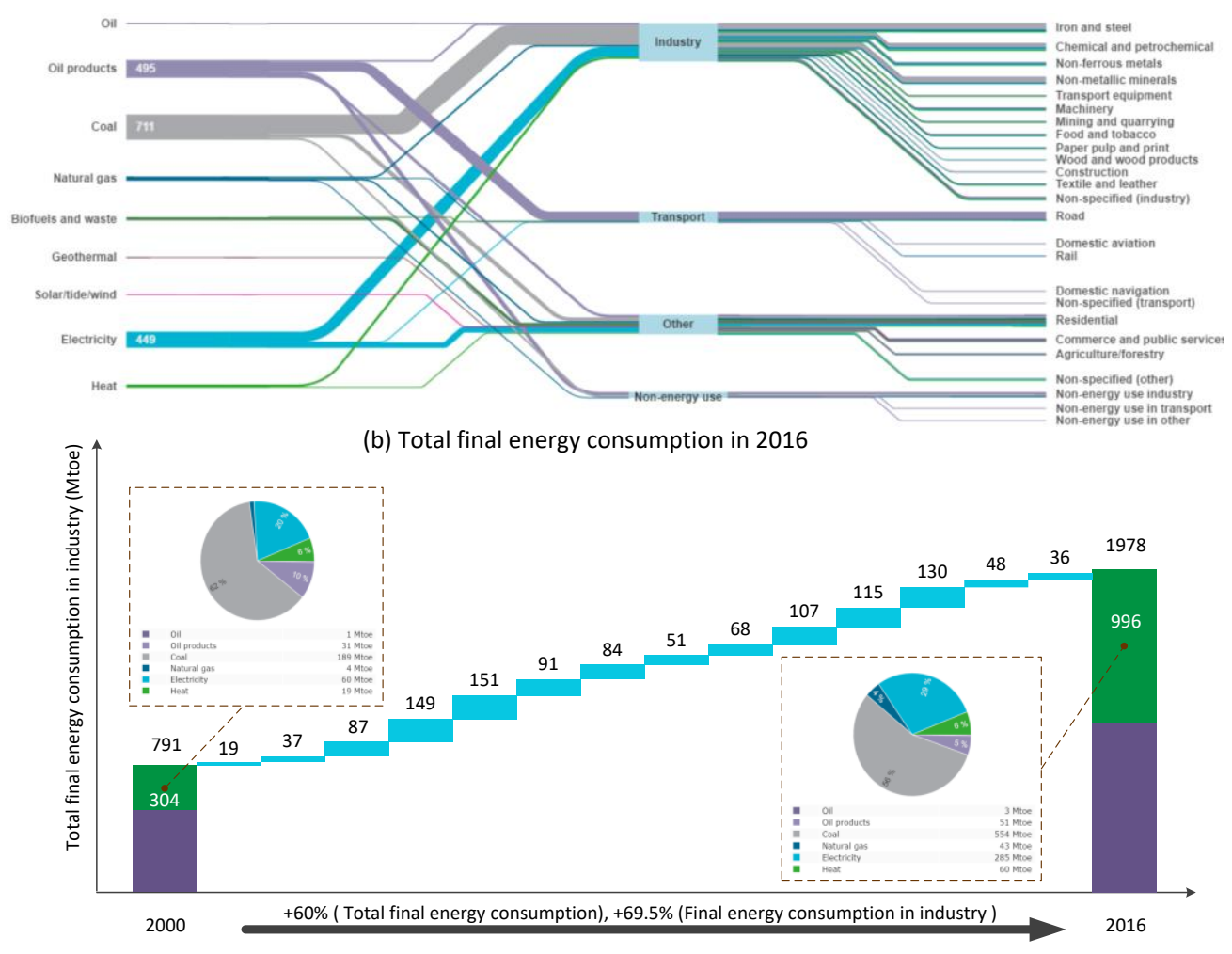

(c) Changes in total final energy consumption from 2000 to 2016

Fig.1 Energy consumption trend from 2000 to 2016. (redrawn with data from [4])

\subsection{Energy efficiency measures}

To promote energy performance of mechanical manufacturing, energy efficiency measures such as energy measurement, monitoring, modelling and optimization have been carried out worldwide with remarkable results achieved. Nevertheless, these existing measures are largely deficient in evaluating and certifying energy performance for the application of specific constraints to energy use. In this paper, we first summarize and analyse existing energy efficiency measures and then review their deficiencies to evaluate the value of energy performance certification.

Energy measurement and monitoring are an effective measure for providing energy data to support reliable operations in any organizations. In mechanical engineering, these data are useful for: (1) establishing environmental performance goals by senior management [19], (2) reducing energy consumption in mechanical manufacturing processes by energy managers, 
(3) using efficiency measures in manufacturing processes by process managers, (4) understanding how to meet customer requirements by suppliers. To control energy use in mechanical manufacturing plant, energy consumption could be measured and quantified in real production processes [20]. Monitoring is a measure to judge and evaluate specific energy consumption as well as a practical energy saving [21]. Energy measurement and monitoring in mechanical manufacturing also has aroused wide research attention. For example, Hu proposed an on-line energy efficiency monitoring method for machine tools [22]. Vijayaraghavan established an approach for realizing automated energy monitoring of machine tools through [23]. Behrendt designed the standardized test procedure of standard test piece with some common machining features, performed the experimental verification, and achieved the energy monitoring processes in mechanical manufacturing [24].

Energy modelling and optimization are basis of studying energy-efficient mechanical manufacturing, and has received researchers' attention. Gutowski analyzed the electrical energy requirements [25] and established the energy models [26]. Kara proposed the specific energy consumption (SEC) models for materials removal, offering an important theoretical basis [27]. Hu studied machining energy consumption from the perspectives of sequencing the features of a part [28] and performing the multi-objective optimization of time, deviation, and energy [29], providing a new method for energy optimization of mechanical manufacturing. Jia presented some energy models from the perspective of the therbligs in machining [30, 31]. Lv proposed a method for reducing energy loss during machining operations [32] and established the energy prediction model in machining [33]. Yoon performed decomposing of energy elements of machine tool and presented an empirical model of energy consumption in milling. [34], and proposed a novel approach for controlling the cost and energy in micro-scale drilling [35]. Mohammed analyzed the specific cutting energy and established the model through reporting on full bandsawing tests to achieve energy efficiency evaluation under different processing materials [36]. Guo performed an optimization method synthetically considering the energy and surface quality in finish turning [37]. Li proposed the definition on fixed energy consumption and study methods for machine tools to promote energy efficiency [38]. Cai investigated the energy efficiency of hobbing machine tools and performed the contrastive analysis among different machine tools [39].

Energy performance evaluation is to quantificationally measure energy efficiency level in production process [40]. However, complexity of mechanical manufacturing processes, the variability of energy consumption, the diversity of application object, and other uncertainties result in the difficulty in analyzing and evaluating energy performance. [41]. Despite all this, studies of energy performance evaluation also make some progresses. For example, Bernard analyzed the energy information of six industries through measuring the input and output of energy use based on principal components analysis [42]. Duflou made a comprehensive review on energy and resource efficiency in manufacturing and advance understanding on energy efficiency improvement [43]. Wang built a multilevel index model of energy efficiency from three levels of the workshop, machine tool, and workpiece [44]. Schudeleit attempted to assess the energy efficiency of machine tools through different approaches [45,46]. Liu structured a series of indictors to evaluate the sustainability of remanufacturing using the emergy 
method [47]. Moreover, there are energy-saving strategies proposed to decrease energy consumption and promote energy efficiency including sustainability design, modelling, and optimization. For example, Diaz introduced some energy -saving strategies to control energy consumption and promote energy efficiency in machining [48]. Li analyzed some factors affecting operational processes and further summarized some effective measures to reduce energy use in machining [49]. Aramcharoen discussed critical factors in energy demand modelling for CNC milling and impact of toolpath strategy [50]. Yoon performed a review on energy consumption analysis, energy efficiency characteristics, energy modelling and energy saving strategies [51].

In sum, energy measurement, monitoring, modelling, optimization, and energy saving strategies have offered important theoretical foundation for studying energy performance in mechanical manufacturing. However, there is a serious lack of study on mechanical manufacturing energy certification due to the difficulty of mechanical manufacturing and energy rules mentioned above.

\subsection{Research gaps}

Energy performance certification is part of the broader use of certification for evaluating and certifying energy performance. This certification approach has been adopted since last century and seen extensive research and remarkable results in various sectors [52-57]. For example, in 2002, the European Union established energy performance of buildings directive, and initiated energy performance certificates for new and existing buildings with the aim to reduce $\mathrm{CO} 2$ emissions further [58-60]. Herrando developed building energy performance certification through analysing the gaps of energy consumption [61]. Taehoon conducted many studies on buildings energy certification, and made important progresses [62,63]. It appears that direct correlation with energy performance certification mainly focuses on the building industry. There are scanty studies on energy performance certification for other industrial sectors, especially for the mechanical manufacturing industry. Even so, there are massive studies on indirect correlation with energy performance certification including energy benchmarking, energy rating, and energy labelling. Previous studies on direct and indirect correlation with energy performance certification in various sectors are summarised in Table 1. Noticeably, study on energy performance certification has become a research focus adapting to the world's sustainable development strategy. 
Tab.1 A selected summary of existing energy performance certification studies in various energy-intensive industries from literature

\begin{tabular}{|c|c|c|c|c|}
\hline Type & Industry & Research method & Specific research object & Sources \\
\hline \multirow{6}{*}{$\begin{array}{l}\text { Direct correla- } \\
\text { tion with energy } \\
\text { performance } \\
\text { certification }\end{array}$} & \multirow{6}{*}{ Building industry } & Strategic energy review & Framework of building energy certification & Pérez-Lombard [64] \\
\hline & & Comparative analysis & Energy certification of buildings & Andaloro [65] \\
\hline & & Embodied energy calculations and live cycle analysis & Building energy regulation and certification in Europe & Casals [66] \\
\hline & & Means of Artificial Neural Networks & Tool for checking energy performance and certification & Buratti [67] \\
\hline & & Comparative analysis & Building energy efficiency certification system & Park [68] \\
\hline & & Geostatistical approach and data-mining technique & Energy performance certificates for existing buildings & Коо [58] \\
\hline \multirow{20}{*}{$\begin{array}{l}\text { Indirect correla- } \\
\text { tion with energy } \\
\text { performance } \\
\text { certification }\end{array}$} & Bio-chemical industry & Analysis of criteria and indicators & Certification on sustainable biomass trade & Lewandowski [69] \\
\hline & \multirow{3}{*}{ Petrochemical industry } & Strategic energy review & Energy benchmarking of petrochemical application & Rikhtegar [70] \\
\hline & & Mathematical modelling & Performance rating system & Rahdari [71] \\
\hline & & Analysis and review & oil shale energy rating & Koitmets [72] \\
\hline & \multirow{2}{*}{ Steel and cement industry } & Analysis & Integrated benchmarking and energy savings tool & Worrell [73] \\
\hline & & - & Energy benchmarking of cement grinding & Zeng [74] \\
\hline & \multirow{2}{*}{ Coal mine industry } & Experimental analysis & Classification and labelling & Skeaff [75] \\
\hline & & Mathematical modeling & Energy efficiency benchmarking system & Wang [76] \\
\hline & Paper industry & Analysis & Benchmarking energy use on process unit level & Laurijssen [77] \\
\hline & \multirow{2}{*}{$\begin{array}{l}\text { Environmental protection in- } \\
\text { dustry }\end{array}$} & Life cycle assessment & Energy and environmental rating of advanced glazing & Papaefthimiou [78] \\
\hline & & Statistical analysis & Energy benchmarking of WWTPs & Krampe [79] \\
\hline & \multirow{2}{*}{ Agricultural and food industry } & Statistical analysis & Certification of food products & Ortega $[80]$ \\
\hline & & Analysis and field survey & Energy utilization of main crop straw resource & Ming [81] \\
\hline & \multirow{4}{*}{ Manufacturing industry } & Analysis and review & Energy training and certification & Glatt [82] \\
\hline & & Analysis and review & Energy labeling for electric fans & Mahlia [83] \\
\hline & & Analysis and modeling & Energy benchmarking rules in machining systems & Cai $[84]$ \\
\hline & & Modeling and Statistical analysis & Dynamic energy benchmark for mass production & Cai [85] \\
\hline & \multirow{3}{*}{ Others } & System modelling & Industrial energy benchmarking & Ke [86] \\
\hline & & Comparison of methods and approach & Energy rating of PV modules & Kenny [87] \\
\hline & & Statistical analysis & China energy label. & Zhou [88] \\
\hline
\end{tabular}


As mentioned, mechanical manufacturing consumes massive energy with low energy ef-

2 ficiency, which has a considerable potential of energy-saving and $\mathrm{CO}_{2}$ emissions mitigation.

3 Realistically, studies on energy performance certification in mechanical manufacturing indus-

4 try are fairly scarce as shown in Table.1, even studies on indirect correlation with energy performance certification like energy benchmarking, rating, and labelling are deficient. Currently,

6 there is a lack of useful tool of energy performance certification for evaluating and certifying 7 energy performance of mechanical manufacturing. For the industry, Liu developed a strategy

8 for energy consumption benchmark of the products regarding the different product types

9 [41]. Cai proposed some energy related benchmarks of the workpiece including the fine en10 ergy consumption allowance and multi-objective energy benchmark to strengthen energy 11 management and promote energy efficiency in machining [89,90]. These studies are discrete, 12 and are not comprehensive for revealing the property of energy performance certification of 13 mechanical manufacturing, and the research gaps mainly include the following three aspects:

- Complexity and variety of the mechanical manufacturing processes result in difficulty in developing energy performance certification due to the lack of a systemic study method.

- The concept and connotation of energy performance certification of mechanical manufacturing are unclear, and its framework and related indicators are imperfect.

- It is unclear how the energy performance certification is implemented to evaluate and certify energy performance in mechanical manufacturing industry and further to improve its energy performance.

\section{1.4 Contributions}

Through analysing existing energy efficiency measures and energy performance certification in industrial section, these methods and measures are considered helpful for energy performance improvement and $\mathrm{CO}_{2}$ emissions mitigation. Due to the deficiency of studying energy performance certification in mechanical manufacturing industry, this paper review and analyse energy performance certification from the perspectives of energy benchmarking, rating, mining and labelling, which is more beneficial to strengthen energy management and improve energy performance. This paper systematically proposed energy performance certification of mechanical manufacturing from several aspects including application scope and data, definition of energy performance certification, classification of energy performance certification, application of energy performance certification, etc. Mastering scope and data of mechanical manufacturing is helpful to understand application objective and complex rules and offer an important basis to acquire database for energy performance certification. Definition of energy performance certification points out the connotation and attributes of energy performance certification. Classification of energy performance certification by different studies provides details of their certification categories including energy benchmarking, rating, mining and labelling to facilitate their implementation in mechanical manufacturing industry. 
1 These studies are useful references for studying energy performance certification. Meanwhile,

2 through application analysis, the proposed energy performance certification not only has

3 wide application prospects in mechanical manufacturing industry, but also plays an important

4 reference role for certification in other fields.

\section{2. Definition of energy performance certification}

To limit $\mathrm{CO}_{2}$ emissions, European Council Directive 93/76/CEE was proposed to promote the development of energy saving and emission reduction [91]. The energy performance certification has been recognised as an effective tool that helps to evaluate and certify energy performance and promote energy performance in industrial sector further [92]. As previously mentioned, the mechanical manufacturing industry has great potential of energy saving.

11 Therefore, energy performance certification of mechanical manufacturing can perform a cru12 cial role in achieving energy conservation in mechanical manufacturing. This energy perfor13 mance certification should comprise a description of manufacturing energy characteristics, 14 offer the energy efficiency information for prospective users, and provide some options for the energy performance improvement.

Due to the non-mandatory directive as well as ambiguities, it is indistinct to how to offer information about manufacturing energy efficiency resulting in difficulty of implementations regarding the requirements. In recent years, the EU acknowledged the need for a new regulatory instrument on the energy performance of industrial sectors. The development of the energy performance certification of mechanical manufacturing was a challenge that has not resolved. Currently, the energy performance certification lacked sufficient detail for a clear and consistent implementation. An energy performance certification definition was vague with two unresolved issues: how to define and how to measure energy performance of mechanical manufacturing.

According to previous studies and perform a comprehensive analysis, the energy performance certification of mechanical manufacturing should comprise some important indicators to reflect the most basic energy performance of the manufacturing product in mechanical manufacturing. Therefore, the energy performance certification of mechanical manufacturing contains at least the following parts and the scheme is as shown in Fig.2.

- An overall energy performance index (EPI) stated in terms of energy consumption, carbon dioxide emissions or energy cost, per unit manufacturing product to allow the comparison between manufacturing processes or systems.

- A minimum energy efficiency performance index ( $\left(\mathrm{EP}_{\mathrm{Min}}\right)$ indictor to describe the best energy performance under different scenarios.

- A label based in the A-E bands of the manufacturing product to quantify a suitable grading of production. 
- Manufacturing product information (MPI) including basis information and manufac-

2 turing information.

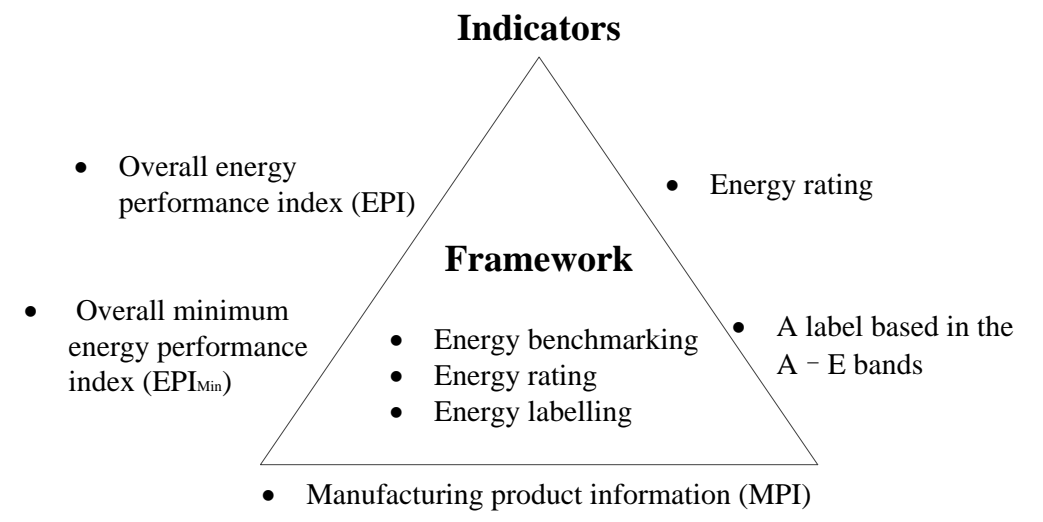

Energy Performance Certification of Mechanical Manufacturing

Fig.2 Framework of energy performance certification of mechanical manufacturing

Thus, the scope of energy performance certification is extended to include not only the energy performance of the mechanical manufacturing but also comprise a minimum requirement and a label or class that allows users to compare and assess prospective manufacturing products.

\section{Scope and data}

\subsection{Scope, processes and energy consumption analysis}

The objective of this paper is to perform a systematic review and analysis on the energy performance certification in mechanical manufacturing industry, and to further discuss the framework comprising the energy benchmarking, rating, and labelling. In this study, the mechanical manufacturing product is considered as a research object or a functional unit. To ensure the application of the energy performance certification, it is necessary to introduce this application boundary. In general, production cycle of one mechanical manufacturing product is in principle a cradle to grave exercise [93]. In the case of the mechanical manufacturing product, the proposed energy performance certification is applicable to many different scenarios such as the cradle to gate, gate to gate, and gate to cradle. More specifically, the whole proposes (from cradle to gate) includes the casting, forging, machining, heat-treating, coating, assembling, etc., from raw materials to qualified products in the workshop. The energy performance certification can be applied to the whole processes (from cradle to gate) or one of gate to gate. The mechanical manufacturing product that is generalized in this study can be either an assembled manufacturing product, a part, or a workpiece. The boundary of production process for the mechanical manufacturing product is shown in Fig.3. Therefore, the object 
1 of the energy certification of mechanical manufacturing is an assembled manufacturing product, a part or a workpiece.

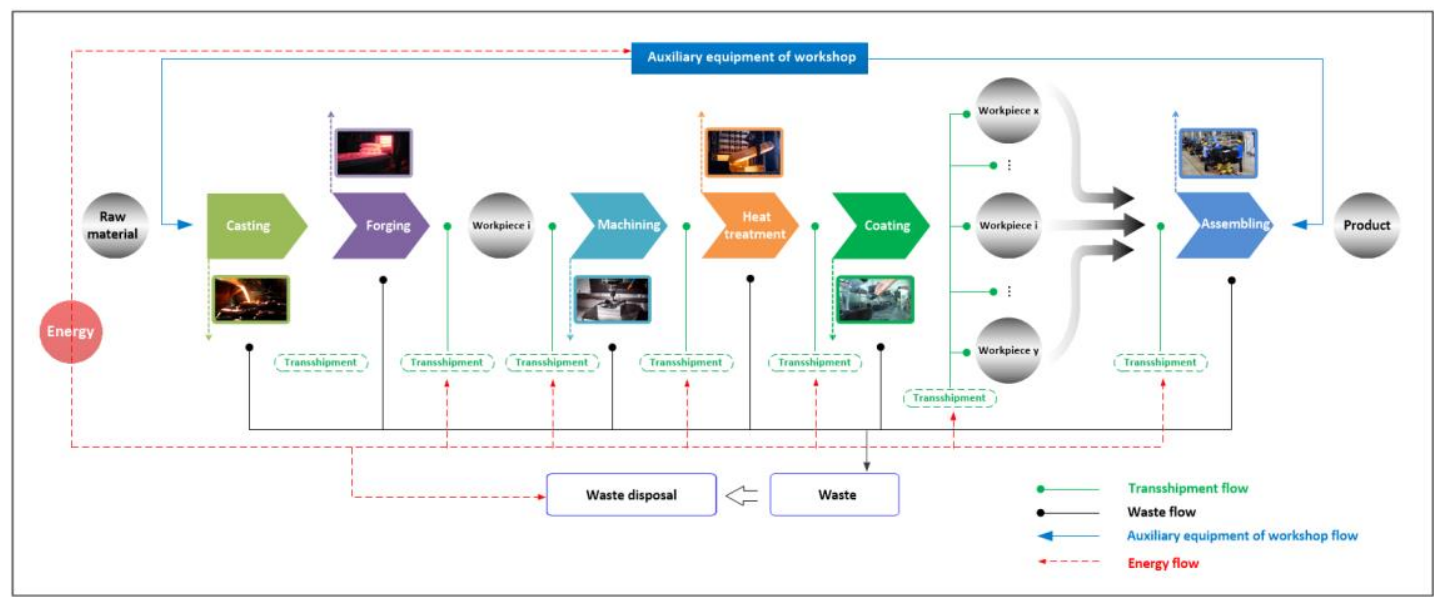

Fig.3 The boundary of production process for the mechanical manufacturing product

The mechanical manufacturing process is fairly complex with various manufacturing equipment, assembly equipment, transhipment equipment and auxiliary equipment, the production process involves the use of various equipment. The manufacturing equipment comprises some casting, forging, machining, heat treatment, coating, and waste disposal equipment [41]. Each type of equipment can be further divided, for example, machining equipment includes lathes, milling machines, planers, grinding machines, and hobbing machines. Each kind of machining equipment has a variety of similar functions with different types like the hobbing machine (i.e. YM3120, YKS3120, YD31125CNC6, YE3120CNC7). The assembly equipment is the assembly of workpieces or parts that have been manufactured, and the assembly equipment includes logistics lines, robots, etc. The transhipment equipment is available for short distance transfer of products, parts, workpieces, and raw materials including automatic conveyer belt, battery car, travelling crane, forklift truck. The auxiliary equipment of the workshop plays an important role in providing the production services including the production environment and drivers. The auxiliary equipment involves lighting, ventilation and heating, air conditioning, water supply equipment and fans, etc. It appears that the complex mechanical manufacturing processes leads to the complexity of energy consumption.

Although mechanical manufacturing processes for manufacturing products are fairly complex, the manufactured product can comprise some parts and some workpieces and that the part can be composed of some parts and workpieces at the next level. By parity of reasoning, the part of the bottom level merely comprises some workpieces. Therefore, energy consumption of the product consists of various energy consumption, such as energy consumption of the workpiece, part, assembling, transhipment, waste disposal and auxiliary equipment of workshop. Energy consumption of a workpiece includes energy consumption of machining, transhipment, waste disposal and auxiliary equipment of workshop. Energy consumption of 
1 the assembling involves energy consumption of logistics lines, robots, etc. Energy consump-

2 tion of the transhipment can be attributed to automatic conveyer belt, battery car, travelling

3 crane, forklift truck, etc. Thus, the product structure tree indicates the characteristics of mul-

$4 \quad$ tiple parts and workpiece and production energy consumption in Fig.4.

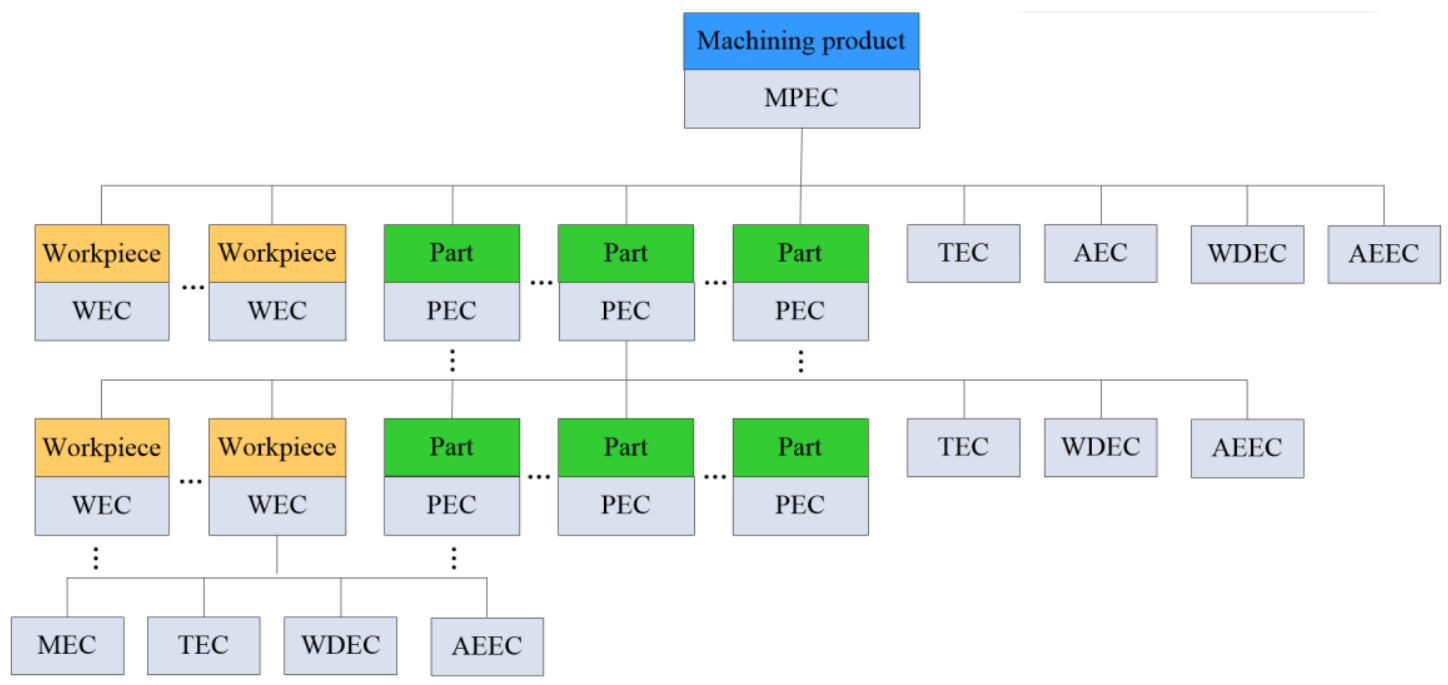

- $\quad$ MPEC (Machining Product Energy Consumption)

- $\quad$ TEC (Transshipment Energy Consumption)

- WEC (Workpiece Energy Consumption)

- WDEC (Waste Disposal Energy Consumption)

- $\quad$ PEC (Workpiece Energy Consumption)

- $\quad$ AEEC (Auxiliary Equipment Energy Consumption)

- $\quad$ AEC (Assembling Energy Consumption)

- $\quad$ MEC (Manufacturing Energy Consumption)

Fig.4 The manufacturing product structure tree and energy consumption [94]

\subsection{Data and analysis}

The energy data is important basis of developing manufacturing energy certification in that studying and collecting energy data is an important basis task. In this study, acquiring energy consumption of the manufacturing product is an important basis of designing and developing energy performance certification that comprises the energy benchmarking, rating, mining, and labelling. The key energy sources principally used in production are electricity, gas energy and other sources, which are used for casting, forging, machining, heat-treating, coating, assembling, etc. The energy consumption differs depending on manufacturing process, for example, from casting to assembling, from machining to heat-treating. As mentioned above, the research scope for manufacturing product is limited from casting to assembling. According to real production process, the involved energy data for manufacturing product need to be collected. To facilitate the analysis of energy consumption in mechanical manufacturing, the factors or variables affecting energy consumption are regarded as independent variables. The $\mathrm{CO}_{2}$ emission density is used as a dependent variable in Table.2. Besides, the energy consumption per manufacturing product can also be modelled as the dependent variable. Considering the unified dimension of multiple energy sources and reflecting the climate change effects, the $\mathrm{CO}_{2}$ emission per manufacturing product is a better measure. However, the 
1 available administrative data does not include the auxiliary energy data like dining room, toi-

2 let, and others. In view of such background, this study determined that energy consumption

3 per unit manufacturing product might be the best measure.

Tab.2 Factors affecting the $\mathrm{CO}_{2}$ emission density of the manufacturing product

\begin{tabular}{ll}
\hline Variables & Descriptions \\
\hline Independent variable & Manufacturing processes (such as casting, forging, machining, heat-treating, \\
& coating, and assembling) \\
& Process plans \\
& Manufacturing equipment \\
& Process routes \\
& Process parameters \\
& $\mathrm{CO}_{2}$ emission density \\
\hline
\end{tabular}

The data comprise a variety of data sources such as energy data and information data, 6 which should be established or collected beforehand. The energy data comprise kinds of en7 ergy sources and amount of each kind of energy. The information data comprise the data of 8 production processes like the amount of manufacturing equipment, process parameters. After data collection, especially for the energy data derived from various energy sources (i.e., electricity and gas energy) for manufacturing product in mechanical manufacturing, unifying dif-

11 ferent energy sources is a basis of analysing the energy consumption and developing the en12 ergy performance certification. In other words, the different energy sources need to be con13 verted into the primary energy consumption or $\mathrm{CO}_{2}$ emission. As mentioned above, the de14 pendent variable $\left(\mathrm{CO}_{2}\right.$ emission density) for each manufacturing product by energy sources can be acquired as follows.

$$
\operatorname{CE}\left(\mathrm{tCO}_{2}\right)=(\text { The amount of electricity consumption }(\mathrm{kWh})) \times
$$

(Carbon dioxide emission factor for eletricity $\left.\left(\frac{\mathrm{tCO}_{2}}{\mathrm{MWh}}\right) \times\left(\frac{1}{10}\right)^{3}\right)$

Where, $\mathrm{CE}$ is $\mathrm{CO}_{2}$ emission for electricity consumption, and $\mathrm{CO}_{2}$ emission factor for electricity energy is $0.4705 \mathrm{t} \mathrm{CO}_{2} / \mathrm{MWh}[55]$.

$$
C G\left(\mathrm{tCO}_{2}\right)=\left(\text { The amount of gas energy consumption }\left(\mathrm{m}^{3}\right)\right)
$$$$
\times\left(\text { Sensible caloric value for gas energy }\left(\frac{\text { Kcal }}{\mathrm{m}^{3}}\right) \times\left(\frac{1}{10}\right)^{7}\right)
$$$$
\times\left(\text { Carbon dioxide emission factor for gas energy }\left(\frac{\mathrm{tC}}{\mathrm{TOE}}\right)\right)
$$$$
\times\left(\text { The ratio of the molecular weight of } \mathrm{CO}_{2} \text { to carbon }\left(\frac{\mathrm{tCO}_{2}}{\mathrm{TC}}\right)\right)
$$

Where, $\mathrm{CG}$ is $\mathrm{CO}_{2}$ emission for gas energy consumption, the sensible caloric value for gas energy is $9420 \mathrm{kKcal} / \mathrm{m}^{3}, \mathrm{CO}_{2}$ emission factor for gas energy is $0.637 \mathrm{tC} / \mathrm{TOE}$, and the ratio of the molecular weight of $\mathrm{CO}_{2}$ to carbon is $44 \mathrm{tCO}_{2} / 12 \mathrm{tC} \mathrm{[55].}$ 
Therefore, the $\mathrm{CO}_{2}$ emission of energy consumption for the manufacturing product can

2 be acquired.

$$
\operatorname{CT}\left(\mathrm{tCO}_{2}\right)=C E\left(\mathrm{tCO}_{2}\right)+C G\left(\mathrm{tCO}_{2}\right)
$$

Where, $C T$ is $\mathrm{CO}_{2}$ emission of total energy consumption for the manufacturing product,

$5 C E$ is $\mathrm{CO}_{2}$ emission of electricity for the manufacturing product, and $C E$ is $\mathrm{CO}_{2}$ emission of gas

6 energy for the manufacturing product. If the production process of manufacturing product

7 involved other energy sources, such as coke, the $\mathrm{CO}_{2}$ emission of energy consumption for man-

8 ufacturing product should the summation of $\mathrm{CO}_{2}$ emission for all energy sources, as follows.

$$
C T\left(\mathrm{tCO}_{2}\right)=C E\left(\mathrm{tCO}_{2}\right)+C G\left(\mathrm{tCO}_{2}\right)+C C\left(\mathrm{tCO}_{2}\right)+C O\left(\mathrm{tCO}_{2}\right)
$$

10 Where, $\mathrm{CC}\left(\mathrm{tCO}_{2}\right)$ is $\mathrm{CO}_{2}$ emission of coke energy for manufacturing product, and

$11 \mathrm{CO}\left(\mathrm{tCO}_{2}\right)$ is $\mathrm{CO}_{2}$ emission of other energy for the manufacturing product.

\section{Classification of energy performance certification}

According to definition of the certification, the certification is a representation of the in-

14 tegrated information, and it comprises various types including the energy benchmarking, rat-

15 ing, mining, and labelling. Therefore, this section attempts to define and clarify concepts of the

16 energy benchmarking, rating and labelling within manufacturing energy classification to de-

17 velop the certification.

\subsection{Energy benchmarking}

\subsubsection{Concept and method of energy benchmarking}

Energy benchmarking is an effective measure and method to describe the energy performance in production [95]. Energy benchmarking has been regarded as one important indicator of energy performance certification and the concept of the energy benchmarking has been studied worldwide. Methods used for establishing energy benchmarks to improve energy per-

24 formance as shown in Table 3. 
Tab. 3. A summary of existing energy benchmarking studies in various energy-intensive industries from the literature

\begin{tabular}{|c|c|c|c|}
\hline Industry & Benchmarking method & Specific research object & References sources \\
\hline \multirow{4}{*}{ Petrochemical industry } & Coupled cluster method & Molecular systems & Řezáč [96] \\
\hline & Mathematical modelling & Industrial glass furnaces & Sardeshpande [97] \\
\hline & Strategic energy review & Petrochemical applications & Rikhtegar [70] \\
\hline & - & Oil and gas wells and cement slurries & Saleh [98] \\
\hline \multirow{2}{*}{ Steel and cement industry } & Mathematical modelling & Iron and steel production & Worrell [73] \\
\hline & - & Cement grinding & Zeng [74] \\
\hline \multirow{4}{*}{ Coal mine Industry } & Mathematical modelling & Mineral Comminution & Nadolski [99] \\
\hline & Mathematical modelling & Dump trucks in mines & Sahoo [100] \\
\hline & Analysis & Copper and gold ores & Ballantyne [101] \\
\hline & Mathematical modelling & Coal production & Wang [76] \\
\hline \multirow{3}{*}{ Pulp and paper industry } & Analysis & Production of paper and board & Laurijssen [102] \\
\hline & k-means & Paper mill & Zhang [103] \\
\hline & Comparative analysis & Kraft pulping mill & Mateos-Espejel [104] \\
\hline \multirow{3}{*}{ Environmental Protection industry } & Comparative analysis & Wastewater treatment plants (WWTP) & Jonasson [105] \\
\hline & Statistical analysis & WWTP & Krampe [79] \\
\hline & Comparative analysis & Dutch industry & Phylipsen [106] \\
\hline \multirow{2}{*}{ Agricultural and food industry } & Mathematical modelling & Frozen food & Prakash [107] \\
\hline & Mathematical modelling & Paddy production & Chauhan [108] \\
\hline \multirow{3}{*}{ Others } & System modelling & - & Ke [86] \\
\hline & Statistical analysis & - & Saygin [109] \\
\hline & Analysis & Various industries in Taiwan & Chan [110] \\
\hline
\end{tabular}


The basic idea of the benchmark is to evaluate and compare the energy performance of

2 two systems which can be as aggregate as manufacturing industry or as disaggregated as spe-

3 cific manufacturing process, and to identify the potential for improving energy efficiency

4 based on the difference between the two systems. Ke proposed a systemic approach for ana-

5 lysing the energy benchmarking [86] in Fig. 5.

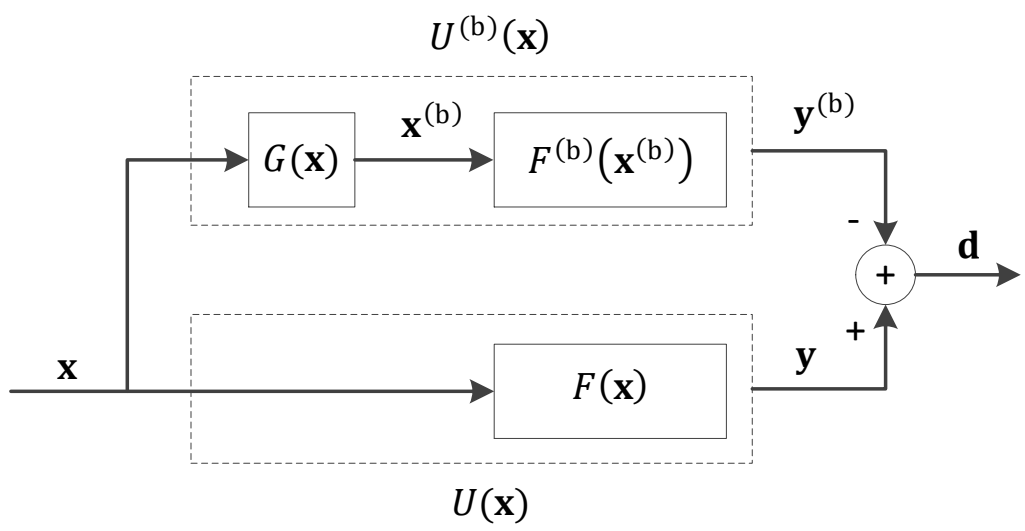

Fig.5 System diagram of general energy benchmarking (Source: [86])

However, for the mechanical manufacturing system, the description is:

$$
\begin{gathered}
\mathbf{y}=F(\mathbf{x})=U(\mathbf{x}) \\
\mathbf{y}^{(\mathrm{b})}=F^{(\mathrm{b})}\left(\mathbf{x}^{(\mathrm{b})}\right)=F^{(\mathrm{b})}(G(\mathbf{x}))=U^{(\mathrm{b})}(\mathbf{x})
\end{gathered}
$$

$$
\text { Where } \mathbf{x}=\left(x_{1}, x_{2}, \ldots, x_{m}\right) \text { and } \mathbf{x}^{(\mathrm{b})}=\left(x_{1}^{(\mathrm{b})}, x_{2}^{(\mathrm{b})}, \ldots, x_{m}^{(\mathrm{b})}\right) \text { are m-dimensional real vectors, }
$$
which influence the factors that represent the manufacturing process (e.g. types of the manufacturing equipment, number of manufacturing equipment, manufacturing parameters). $G(\mathbf{x})$ is the function translating the control variable $\mathbf{x}$ to $\mathbf{x}^{(b)} \cdot \mathbf{y}=\left(y, y_{2}, \ldots, y_{n}\right)$ and $\mathbf{y}^{(b)}=$ $\left(y_{1}^{(b)}, y_{2}^{(b)}, \ldots, y_{n}^{(b)}\right)$ are n-dimensional real vectors that represent the $\mathrm{CO}_{2}$ emission and the corresponding energy benchmarking, respectively. $\mathbf{y}=F(\mathbf{x})$ and $\mathbf{y}^{(\mathrm{b})}=F^{(b)}\left(\mathbf{x}^{(\mathrm{b})}\right)$ are $\mathrm{CO}_{2}$ emission models of manufacturing systems and the energy benchmarking to be evaluated, respectively. $U(\mathbf{x})=F(\mathbf{x})$ and $U^{(b)}(\mathbf{x})=F^{(b)}(G(\mathbf{x}))$ are the composite function.

In manufacturing processes, $\mathrm{CO}_{2}$ emission $\mathrm{CT}\left(\mathrm{tCO}_{2}\right)$ and energy benchmarking $C T\left(\mathrm{tCO}_{2}\right)^{(b)}$ of the base process is:

$$
\begin{gathered}
C T\left(\mathrm{tCO}_{2}\right)=K(\mathbf{y}) \\
C T\left(\mathrm{tCO}_{2}\right)^{(b)}=K^{(b)}\left(y^{(b)}\right)
\end{gathered}
$$

Where, $K($.$) is the function of calculated \mathrm{CO}_{2}$ emission.

Thus, the total $\mathrm{CO}_{2}$ emission of the whole manufacturing processes of the product $C T\left(\mathrm{tCO}_{2}\right)_{\text {Total }}$ and energy benchmarking $\operatorname{CT}\left(\mathrm{tCO}_{2}\right)_{\text {Total }}^{(b)}$ are:

$$
C T\left(\mathrm{tCO}_{2}\right)_{\text {Total }}=C T\left(\mathrm{tCO}_{2}\right)_{1}+\operatorname{CT}\left(\mathrm{tCO}_{2}\right)_{2}+\cdots+C T\left(\mathrm{tCO}_{2}\right)_{N}=\sum_{i}^{N} C T\left(\mathrm{tCO}_{2}\right)_{i}
$$




$$
\operatorname{CT}\left(\mathrm{tCO}_{2}\right)_{\text {Total }}^{(b)}=K\left(\operatorname{CT}\left(\mathrm{tCO}_{2}\right)_{\text {Total }}\right)=K\left(C T\left(\mathrm{tCO}_{2}\right)_{1}+C T\left(\mathrm{tCO}_{2}\right)_{2}+\cdots+C T\left(\mathrm{tCO}_{2}\right)_{N}\right)=
$$

$$
K\left(\sum_{i}^{N} \mathrm{CT}\left(\mathrm{tCO}_{2}\right)_{i}\right)
$$

Through development of the system modelling of energy benchmarking, the approach

4 provides a general unified framework for studying energy benchmarking in mechanical man-

5 ufacturing and offers an affinitive study tool.

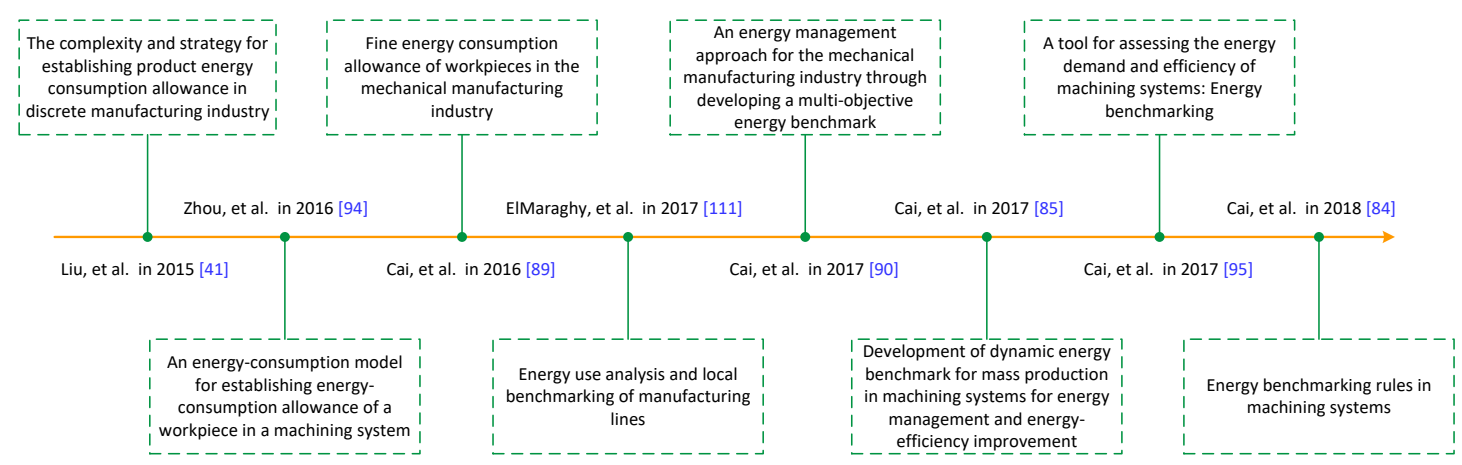

$7 \quad$ Fig.6 A summary of existing energy benchmark studies in mechanical manufacturing

8 The related studies on energy benchmarking in the mechanical manufacturing industry

9 are inadequate [111], and achieve some progresses. A summary of existing energy benchmark

10 studies is as shown in Fig.6.

\section{4.1.2 Energy benchmarking and classification}

12 On the basis of summarizing these studies, we proposed a systemic energy benchmarking 13 for the manufacturing product. The energy benchmarking can be represented using the $\mathrm{CO}_{2}$ 14 emission of manufacturing product. The benchmarking includes different aspects in Table.4. 
Tab.4 The energy benchmarking of mechanical manufacturing product from the different aspects

\begin{tabular}{|c|c|c|c|c|c|c|}
\hline $\begin{array}{l}\text { Different requirement types for } \\
\text { benchmarking }\end{array}$ & Benchmarking & $\begin{array}{c}\text { One Kind of } \\
\text { benchmarking }\end{array}$ & $\begin{array}{l}\text { Multiple bench- } \\
\text { marking }\end{array}$ & Benchmarking & $\begin{array}{r}\text { One Kind of } \\
\text { benchmarking }\end{array}$ & $\begin{array}{l}\text { Multiple bench } \\
\text { marking }\end{array}$ \\
\hline Production cycle aspect & $\begin{array}{l}\text { Entire production cycle } \\
\text { benchmarking }\end{array}$ & $\bullet$ & $\circ$ & $\begin{array}{l}\text { A certain production stage } \\
\text { benchmarking }\end{array}$ & $\circ$ & $\bullet$ \\
\hline $\begin{array}{c}\text { Production objective } \\
\text { aspect }\end{array}$ & $\begin{array}{l}\text { Single objective bench- } \\
\text { marking }\end{array}$ & $\bullet$ & $\circ$ & $\begin{array}{l}\text { Multiple objectives bench- } \\
\text { marking }\end{array}$ & $\circ$ & $\bullet$ \\
\hline Benchmarking evaluation aspect & Static benchmarking & - & o & Dynamic benchmarking & $\circ$ & - \\
\hline
\end{tabular}


(1) Production cycle aspect

The $C T_{M P}$, which is total energy performance that is total $\mathrm{CO}_{2}$ emission for the manufacturing product comprising all energy sources, and it can be determined as the total energy benchmarking of the manufacturing product. The $C T_{\text {mamufacturing product }}$ is regarded as an entire production cycle benchmarking. However, in the actual production processes, the energy consumption of each production procedure such as the casting, forging and machining procedure, even Auxiliary equipment of workshop, need to be cared or considered to improve the corresponding energy performance by some measures and control methods. Therefore, the benchmarking of each production procedure, which is a certain production stage benchmarking, need to established. The benchmarking can be expressed by $C T_{\text {casting }}, C T_{\text {forging }}$, $C T_{\text {machining }}, C T_{\text {heat-treating, }} C T_{\text {coating }}, C T_{\text {assembling }}$ and $C T_{\text {others }}$. Therefore, these energy benchmarking can be determined as follows:

$$
C T_{\text {casting }}\left(\mathrm{tCO}_{2}\right)=C E_{\text {casting }}\left(\mathrm{tCO}_{2}\right)+C G_{\text {casting }}\left(\mathrm{tCO}_{2}\right)+C C_{\text {casting }}\left(\mathrm{tCO}_{2}\right)+
$$

$$
\mathrm{CO}_{\text {casting }}\left(\mathrm{tCO}_{2}\right)
$$

$$
C T_{\text {forging }}\left(\mathrm{tCO}_{2}\right)=C E_{\text {forging }}\left(\mathrm{tCO}_{2}\right)+C G_{\text {forging }}\left(\mathrm{tCO}_{2}\right)+C C_{\text {forging }}\left(\mathrm{tCO}_{2}\right)+
$$

$$
\mathrm{CO}_{\text {forging }}\left(\mathrm{tCO}_{2}\right)
$$

Meanwhile, other energy benchmarking also can be determined, therefore, the entire production cycle benchmarking of the manufacturing product is calculated

$$
\begin{array}{r}
C T_{M P}\left(\mathrm{tCO}_{2}\right)=C T_{\text {casting }}\left(\mathrm{tCO}_{2}\right)+C T_{\text {forging }}\left(\mathrm{tCO}_{2}\right)+C T_{\text {machining }}\left(\mathrm{tCO}_{2}\right)+ \\
C T_{\text {heat-treating }}\left(\mathrm{tCO}_{2}\right)+C T_{\text {coating }}\left(\mathrm{tCO}_{2}\right)+C T_{\text {assembling }}\left(\mathrm{tCO}_{2}\right)+C T_{\text {others }}\left(\mathrm{tCO}_{2}\right)
\end{array}
$$

(2) Production objective aspect

The energy benchmarking of the manufacturing product is related to production technology. The energy usage of the product is very different with various production technology resulting in difference in energy benchmarking.

The production technology is closely related to the production objectives such as production time (PT), cost of production technology (CPT), production quality (PQ). In general, the firm pursues a comprehensive goal that it is good for each indictor like energy, PT, CPT, and $P Q$. [90]. The production objectives are different, and there is an even bigger difference among production processes. Therefore, the energy benchmarking comprises two kinds of benchmarking: single objective benchmarking ( $\mathrm{SOB}$ ) and multiple objectives benchmarking (MOB). The single objective benchmarking mainly considers the energy usage, but the multiple objectives benchmarking integrated considers some or all objectives of PT, CPT, PQ, and EP besides energy usage.

The usual energy benchmarking is regarded as the SOB, and it is a kind of universal benchmarking. The description of the SOB is:

$$
C T_{M P}\left(\mathrm{tCO}_{2}\right)_{S O B}=Y[\underbrace{f(x)}_{S_{i}}]
$$


1 Where, $C T_{M P}\left(\mathrm{tCO}_{2}\right)_{S O B}$ is total $\mathrm{CO}_{2}$ emission of the single objective benchmarking for the

2 manufacturing product. $Y[\cdot]$ is the calculation function of $\mathrm{CO}_{2}$ emission. $\underbrace{f(x)}_{S_{i}}$ is the function of

3 the production process considering the single objective $S_{i} \cdot x$ is process parameters. Therefore,

4 if the firm only considers the production cost (C) as the production objective, the description

5 of the SOB is as shown in E. q (15); If only considers the production efficiency (T) as the pro-

6 duction objective, the description is as shown in E. q (16)

7

$$
\begin{aligned}
& C T_{M P}\left(\mathrm{tCO}_{2}\right)_{S O B}=Y[\underbrace{f(x)}_{C}] \\
& C T_{M P}\left(\mathrm{tCO}_{2}\right)_{S O B}=Y[\underbrace{f(x)}_{T}]
\end{aligned}
$$

However, the MOB is more complex compared with the SOB. The MOB can be determined

10 by integrated evaluation method such as TOPSIS method. The method for acquiring the MOB

11 is as shown in Fig.7. 


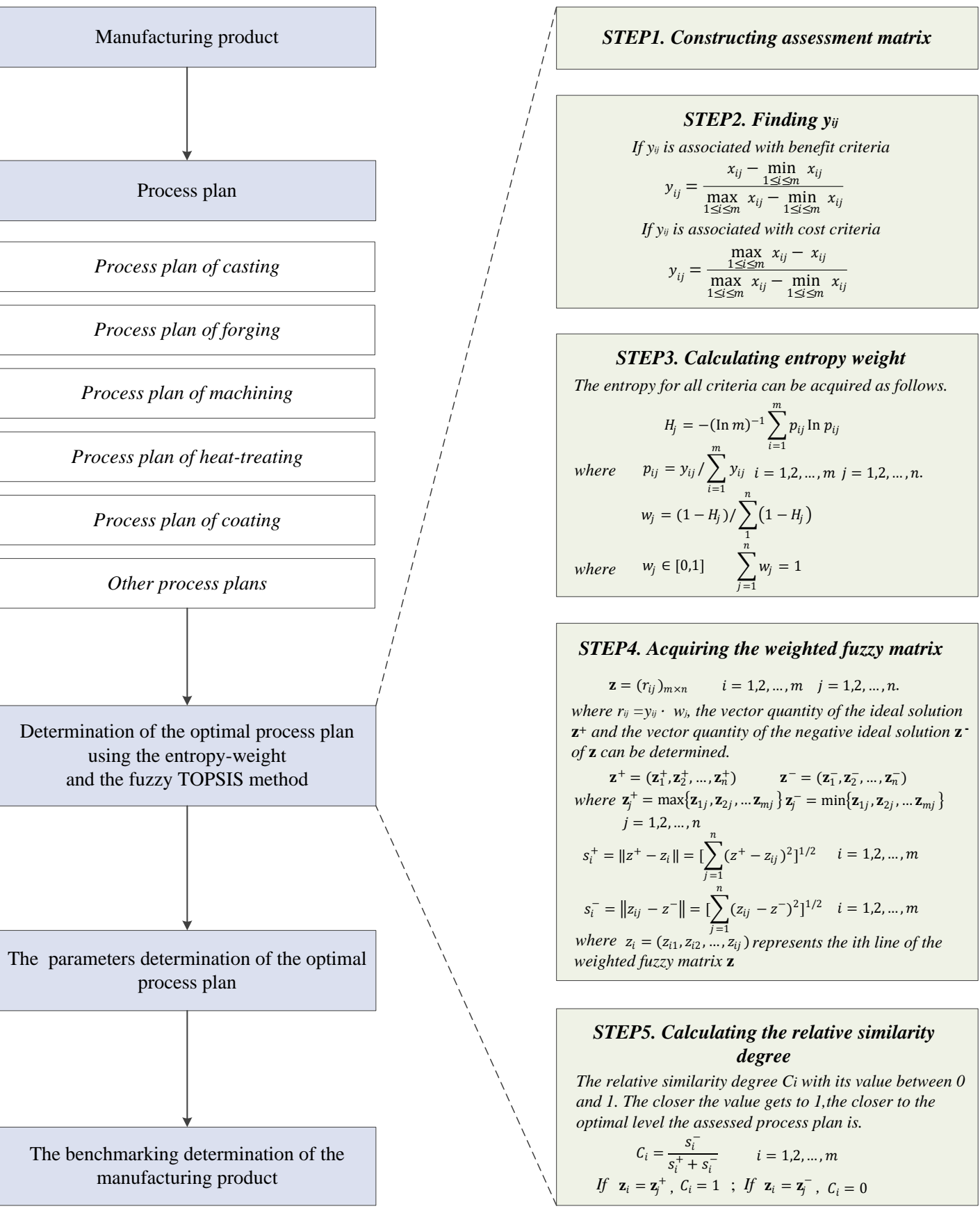

Fig. 7 The method for acquiring the MOB

(3) Benchmarking evaluation aspect

In the application phase of the benchmarking evaluation, the energy benchmarking can

5 be divided into the static benchmarking and dynamic benchmarking. The static benchmarking

6 is a conventional benchmarking interpreting the relationship between a product and its en-

7 ergy consumption by a numerical value, similar to the relationship between manufacturing

8 one product and the energy usage of that product. Unnecessary energy of the production pro-

9 cesses can be identified by comparing the actual $\mathrm{CO}_{2}$ emission with the benchmarking. $\mathrm{CO}_{2}$

10 emission can be controlled and reduced by identifying useful measures using static bench- 
marking in the production processes. Static benchmarking is one of the most widely used ap-

2 proaches [85]. However, for the static benchmarking, whether production processes or subprocesses satisfy the criterion is ultimately judged by the comparison between the actual energy usage and the benchmarking. The static benchmarking is beneficial for promoting energy management and energy efficiency.

Compared with the static benchmarking, the dynamic benchmarking is the improvement and evolution of static benchmarking. Cai proposed the dynamic energy benchmarking and gave the definition that dynamic energy benchmark is a metric for the standardised evaluation of the energy consumption for the same production target in a different environment [85]. Cai introduced the scope and application boundary for dynamic energy benchmarking, and analyzed the characteristics [85]: Dynamic benchmarking considers all energy circumstances of product under the various production plans and is applicable to the production of a single product with different manufacturing equipment. The dynamic benchmarking is an integrated benchmarking that can reflect the energy level contributing to achieving maximum utilisation of production equipment. Dynamic benchmarking can quantify the energy level of each production plan for the same unit manufacturing product under different product plans.

Dynamic benchmarking can be described:

$$
\eta=C T_{A}\left(\mathrm{tCO}_{2}\right) \cdot \frac{1}{C T_{B}\left(\mathrm{tCO}_{2}\right)} \cdot 100
$$

Here, $\eta$ represents the benchmarking rating of the manufacturing product, $C T_{A}\left(\mathrm{tCO}_{2}\right)$ represents the $\mathrm{CO}_{2}$ emission of the manufacturing product by all energy sources in manufacturing, and $C T_{B}\left(\mathrm{tCO}_{2}\right)$ stands for the benchmarking of the manufacturing product.

Establishment of the dynamic benchmarking can offer effective help for developing the energy rating system and energy labelling.

\section{$24 \quad 4.2$ Energy rating}

\section{4.2.1 Concept and method of energy rating}

Rating is a description of manufacturing energy classification or rating figure (expression energy rating system) [112]. In general, the energy rating system (ERS) is a synonym of energy classification that is a measure to evaluate energy performance. For example, in the building sector, the energy rating system can evaluate the energy level for building energy use. In the manufacturing industry, the ERS can serve as a method for the assessment of predicted energy use, and energy use prediction, rating score.

Tab. 5 Energy ratings and classification

\begin{tabular}{lllll}
\hline Rating type & Rating subtype & Based on & Pattern of use & Project stage \\
\hline \multirow{2}{*}{ Standard } & Design & Calculations & Standard & Design \\
& Manufacturing & Calculations & Standard & Manufacturing \\
Tailored & - & Calculations & Non-standard & Manufacturing \\
\hline
\end{tabular}




Measured or operational $\quad-\quad$ Metered amounts $\quad$ Actual activity $\quad$ Manufacturing

For the standard EN 15603 [21], CEN presents two types of ratings including the calcu-

2 lated ratings and measured (or operational) ratings. The calculated ratings are based on the

3 computer or model calculations to predict energy used, and calculated ratings are subdivided into standard and tailored ratings. The measured (or operational) ratings are based on real metering on-site. Therefore, the ratings can be applied to the manufacturing product in Table 5. The standard ratings include the rating subtype of design and manufacturing and these are based on the calculations. The other tailored ratings also are based on the calculations and are non-standard of pattern of use. The measured (or operational) ratings are derived from metered amounts as an actual activity of pattern of use.

Energy performance certification schemes for the manufacturing product are usually implemented by standard ratings. For the manufacturing product, both calculated and measured ratings are applicable, but the latter is preferred to reduce energy performance discrepancies and limit production risks due to uneconomic production investment or credibility problems if stakeholders conclude that energy rating system are less accurate than expected. For the manufacturing product, the ratings can be described.

$$
\eta=C T_{A}\left(\mathrm{tCO}_{2}\right) \cdot \frac{1}{C T_{B}\left(\mathrm{tCO}_{2}\right)} \cdot 100
$$

The energy rating is also the benchmarking rating as mentioned. Besides, the energy rating can be further improved, on basis of Eq. (18)

$$
\alpha=\frac{\left|C T_{B}\left(\mathrm{tCO}_{2}\right)-\overline{C T_{o}\left(\mathrm{tCO}_{2}\right)}\right|}{C T_{B}\left(\mathrm{tCO}_{2}\right)}
$$

(1)

(1)

2

3

common energy-saving potential range, $\Delta$ is evaluation grade range, $N$ is the number of the evaluation grade, $a_{0}$ is the upper limit of common energy-saving potential range, $\alpha_{1}$ is uncommon energy-saving potential range, $\alpha_{2}, \alpha_{3}$, and $\alpha_{N-1}$ are common energy-saving potential range, and $\alpha_{N}$ is the unqualified range exceed the benchmarking. Authors previous study pointed out that especially for the Eqs. (19) and (20), $\overline{C T_{o}\left(\mathrm{tCO}_{2}\right)}$ can be achieved through op-

33 timization methods, either of the process parameters optimization and the change of manu34 facturing equipment. $N$ usually is 4 or $5 . \alpha_{1}$ is the most excellent energy-saving potential 
1 range. $\alpha_{2}, \alpha_{3}$, and $\alpha_{N-1}$ gradually become bad for the energy-saving potential, and $\alpha_{N}$ is worst.

2 For the energy rating and method, it can offer an important help for developing the energy

3 labelling.

$4 \quad$ 4.2.2 Energy rating system

5 The energy rating is a basis of designing and developing the energy rating system. The

6 design of energy rating system has a similarity in different fields. For example, in the building,

7 U.K. issues designs the energy performance certificate (DEC) in the form of standardized value

$8(0-150)$ for a building's CO2 emissions [55], which is categorized into seven grades from A to

$9 \quad$ G in Fig.8.

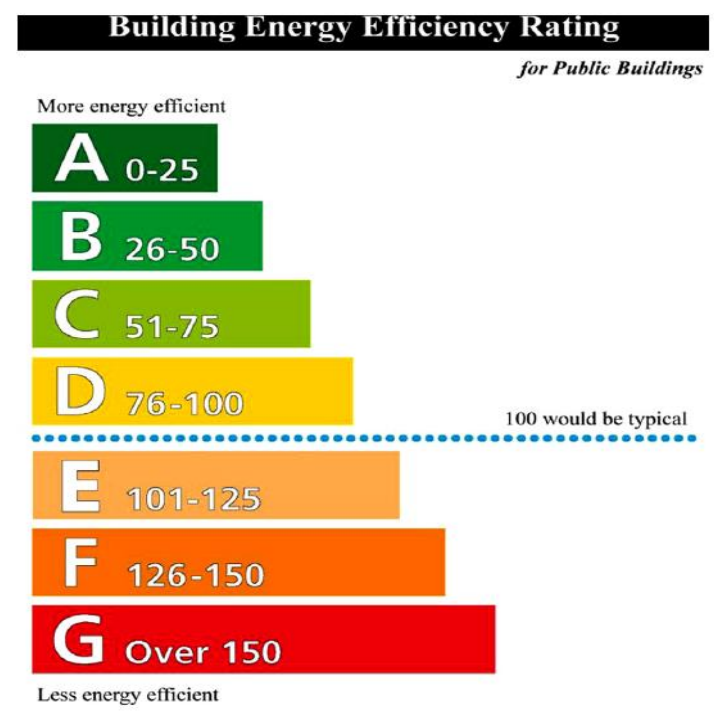

Fig.8 Building EPCs for the operational rating in the UK (Source: [55])

In mechanical manufacturing industry, energy rating system is established as shown in 13 Fig.8. Such system is applied to the machining and the functional unit considered is one work14 piece that is a typical mechanical manufacturing product [85,90]. Fig.8 employs five grades 15 from $\mathrm{A}$ to $\mathrm{E}$, and the energy rating is not unique and is determined according to the require16 ments of the firm, district government, and nation. Actually, the method for establishing en17 ergy rating system is similar and that only the objects are different, regardless of mechanical 18 manufacturing industry or building industry. Similarly, the application of energy rating sys19 tem can be extended in terms of requirement, for example, the integration of energy consumption and time can be described in the energy rating system as seen in Fig.9. 


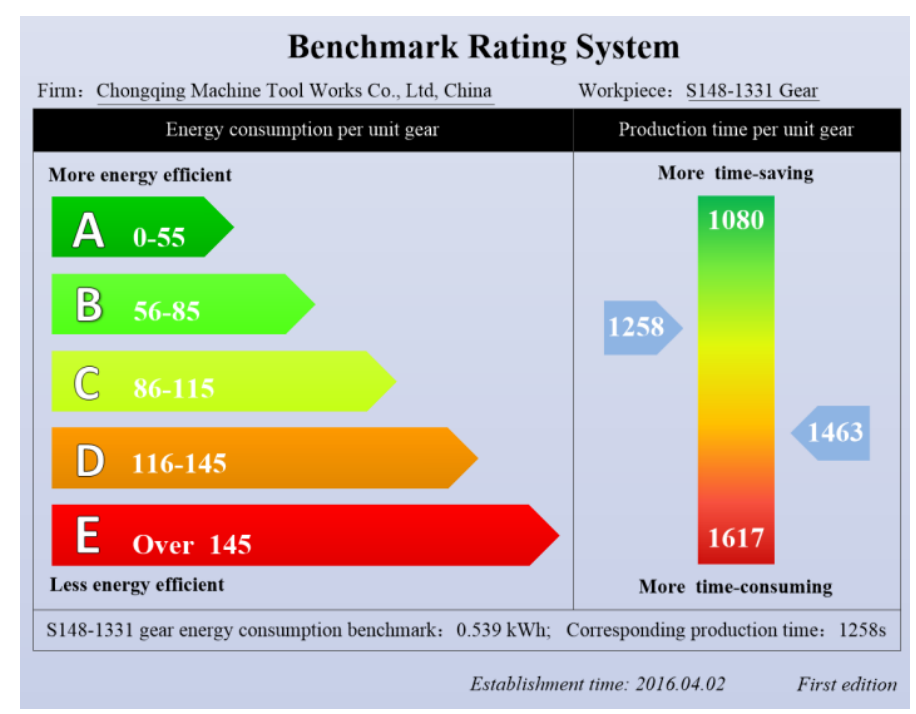

Fig.9 Application of energy rating system integrating energy consumption and time (source:

\section{$4 \quad 4.3$ Energy labelling}

The energy labelling was introduced by the EU in the early 1990s with a double objective: to inform consumers about the energy performance of energy consuming devices and to promote energy savings and energy efficiency. Currently, the energy labelling has been developed rapidly and extended to various industries [59].

Manufacturing energy labelling is regarded as an important index of energy performance certification of the mechanical manufacturing. Mechanical manufacturing energy labelling can

11 be regarded as an energy performance class or label to the product and requires the develop12 ment of a scale related to a manufacturing labelling index (MLI). Analysing the manufacturing 13 scenario by comparison is the basis of determining the MLI. If there are enough comparable 14 manufacturing products, statistical analysis of the EPI through the cumulative frequency dis15 tribution curve allows the use of the percentile as an indicator of the energy position. At this point, labelling is equivalent to SEC distribution of cumulative frequencies using an average value such us the percentile of $50 \%\left(\mathrm{EPI}_{50}\right)$ the labelling index could be defined as:

$$
\mathrm{MLI}=\frac{\mathrm{EPI}}{\mathrm{EPI}_{50}}
$$

The scale is defined by fixing the transition values between classes, $\operatorname{MLI}_{\mathrm{ij}}$. Fig. 10 is a pos-

20 sible scale of 5 bands over the labelling index distribution curve. However, the scale of 5 bands

21 is non-unique, and the scale that may be 6 or 7 bands is determined according to the requirements. 


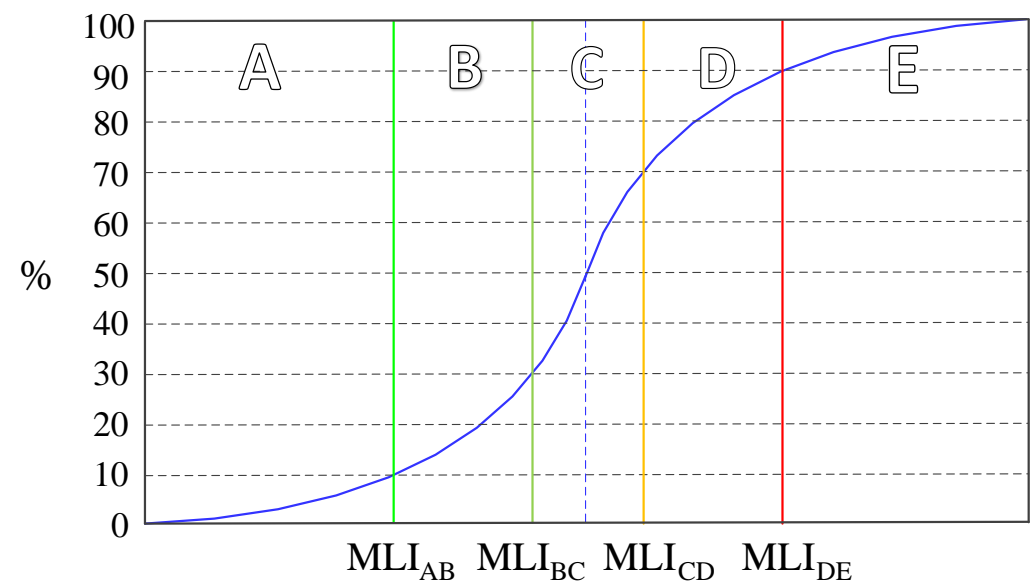

Fig.10 Labelling scale and cumulative frequency curve of MLI

For the energy performance of the manufacturing product, the MLI depends on two references indexes [63]. The first index is the overall minimum efficiency requirement set by the regulation (or optimization) as a maximum limit for the energy performance index (EPI > $6 \quad \mathrm{EPI}_{\mathrm{r}}$ ); The second index corresponds to the energy performance reached by $50 \%$ of the man7 ufacturing product $\left(\mathrm{EPI}_{\mathrm{m}}\right)$. If the EPI is normalized by the manufacturing product reference, 8 the label index for the regulation reference is:

$$
\mathrm{MLI}_{r}=\frac{\mathrm{EPI}_{r}}{\mathrm{EPI}_{\mathrm{m}}}=\alpha
$$

In the real application, regulation developers should assure a certain saving percentage $11(1-\alpha)$ ahead manufacturing product to improve energy performance. According to analysis 12 of this methodology CEN's scale [63], the classes for the scale is as follows in Table.6.

Tab.6 Limits between classes for the scale proposed by CEN.

\begin{tabular}{cccc}
\hline $\mathrm{MLI}_{\mathrm{AB}}$ & $\mathrm{MLI}_{\mathrm{BC}}$ & $\mathrm{MLI}_{\mathrm{CD}}$ & $\mathrm{MLI}_{\mathrm{DE}}$ \\
$0.5 \alpha$ & $\alpha$ & $0.5(1+\alpha)$ & 1
\end{tabular}

14 Criteria to set the scale are subjective and, perhaps, closer to policy decisions than to 15 technical analysis. Thus, there is great disparity between different scales. A key issue is the 16 level of definition or number of classes. Fig. 11 shows a comparison of the saving percentages 17 of four different labelling scales for classes ahead a certain reference. The CEN's scale refer18 ence is set by the regulations for different energy performance certification [113]. 


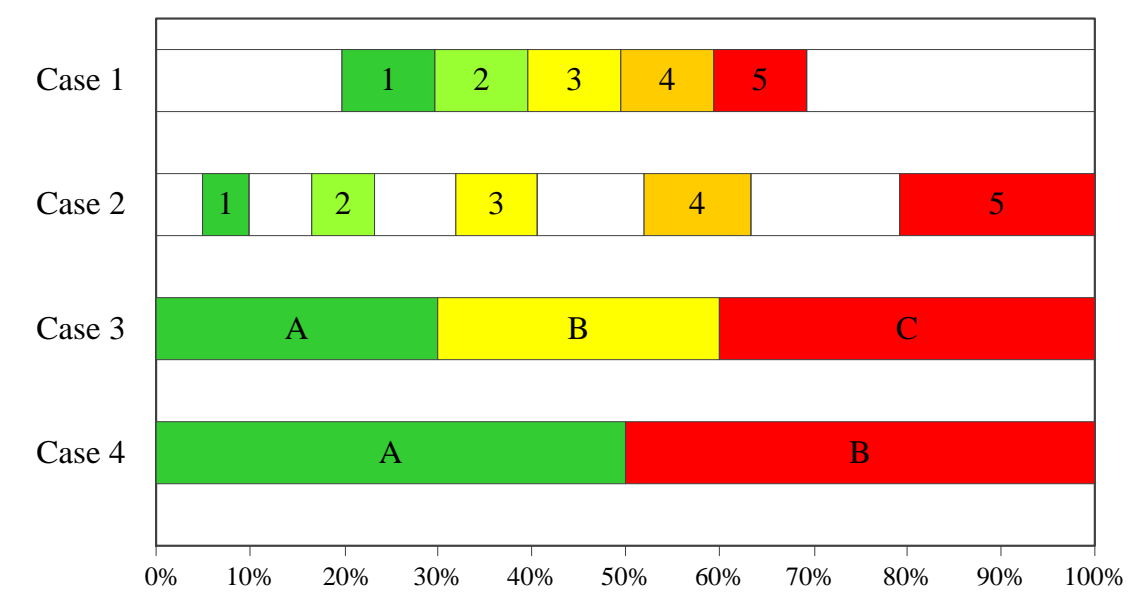

Fig.11 Comparison of energy scales of different certifications schemes in terms of saving percentage ahead certain reference.

Therefore, the energy labelling can be designed and developed as an important part of energy performance certification in terms of the calculated methods above. The energy labelling system are shown with more detail in section 5 .

\section{Application of energy performance certification}

\subsection{Analysis on key issues for energy performance certification}

(1) Assessing energy efficiency of mechanical manufacturing

The energy efficiency is a measurement expressing the idea of consuming less energy while providing better services [63]. The energy efficiency is a ratio of energy input to service output and can be determined by calculation and measurement. However, evaluating the energy efficiency in mechanical manufacturing are a complex task because the complexity and variability of energy processes can lead to difficulty in the definition and measurement of energy efficiency. The energy performance indicators have been regarded as a substitute in energy efficiency analysis. Therefore, for the energy performance certification of mechanical manufacturing, the first step is to consider and determine the energy performance indicators. The indicators can be selected flexibly regarding the practical conditions, such as energy consumption per product, the ratio of energy utilization per product, $\mathrm{CO}_{2}$ emission.

(2) Acquiring the energy data in mechanical manufacturing

Obtaining the energy data is a basic step to achieve the development of energy performance certification, and its methods are subdivided into prediction, on-line measurement, and analogy analysis.

The prediction method is mainly to build a mathematical model and to calculate energy. This approach is easier to acquire corresponding data focused on an objective, which can be 
1 adapted to various manufacturing product including the unprocessed and processed produc-

2 tion with wide application. The on-line measurement method can collect the data that has high

3 accuracy by the measuring instrument, but this method is not adapted to the unprocessed

4 manufacturing product without data. The analogy analysis method focuses on the analysis and

5 evaluation of previous energy data of other products that have similar characteristics for each

6 production process compared with current production processes of the product. But, this

7 method has strong professional capacity and it is difficult to find similar products and data to

8 match with the current product. Three kinds of approaches for data collection are summarized

9 in Table 7. The specific methods are selected in terms of actual requirements. 
Tab.7 Differences among different methods

\begin{tabular}{|c|c|c|c|c|c|c|c|c|c|}
\hline \multirow[t]{2}{*}{ Methods } & \multicolumn{2}{|c|}{ Applicability } & \multicolumn{2}{|c|}{$\begin{array}{l}\text { Opera- } \\
\text { bility }\end{array}$} & \multicolumn{2}{|c|}{$\begin{array}{l}\text { Model Require- } \\
\text { ments }\end{array}$} & \multicolumn{3}{|c|}{ Data Reliability } \\
\hline & Unprocessed product & Processed product & Low & High & Low & High & Bad & Good & Excellent \\
\hline Prediction Method & $\bullet$ & $\bullet$ & & $\bullet$ & & $\bullet$ & & $\bullet$ & \\
\hline On-line Measurement & & $\bullet$ & $\bullet$ & & $\bullet$ & & & & $\bullet$ \\
\hline Analogy Analysis & $\bullet$ & $\bullet$ & & $\bullet$ & $\bullet$ & & $\bullet$ & & \\
\hline
\end{tabular}


(3) Comparing the energy performance of mechanical manufacturing

2 On basis of acquiring the energy performance indicators, to establish the energy rating 3 or energy labelling, a sample of buildings for comparison should be found. Definition of com-

4 parison scenario is fairly important for implementation of energy performance certification.

5 The vital issues is whether the EPI of a wide number of processed products is available, and 6 processed products are identity for current product. For the affirmative answer, the compar7 ison is feasible and a certain degree of similarity between products to be compared must be

8 set, and the product must be same without caring the production process. The product could 9 be in different plants, but in a same firm.

10 (4) Labelling for energy efficiency of mechanical manufacturing

11 Classifying energy performance of mechanical manufacturing related to the comparison 12 scenario could be determined through assigning an energy label. Firstly, the manufacturing 13 labelling index (MLI) should be defined. Given that the sample for comparison is available, MLI 14 can be defined as the ratio of the EPI of the mechanical manufacturing to the EPI average value 15 of the sample. According to Fig.11, the manufacturing label index shows the saving percentage 16 in relation to the reference mechanical manufacturing performance. Secondly, the limits be17 tween classes on the label index frequency curve should be set by synthetically considering 18 the saving percentages.

19 (5) What information should the energy performance certification include?

20 The energy performance certification is a concept affecting the energy performance and 21 mainly includes four kinds of energy information (i.e. energy benchmark, energy rating, en22 ergy mining, and energy labelling). In real-life application, energy performance certification 23 includes at least the energy benchmark and energy label. In order to assess what other infor24 mation should be included, three categories of information according to its final use are (1) 25 administrative data such as process data and procedure information; (2) energy mining infor26 mation and energy saving level; (3) the overall minimum energy performance index EPI $\mathrm{Min}_{\text {. }}$

\section{$27 \quad 5.2$ Case analysis}

28 This case analysis introduces the development of energy performance certification, and 29 discusses the practicability for a real production. Due to a wide variety of energy performance certification and obvious differences in application under different circumstances, this part 31 mainly introduces energy benchmarking, energy rating, and energy labelling for a common 32 part in mechanical manufacturing. 

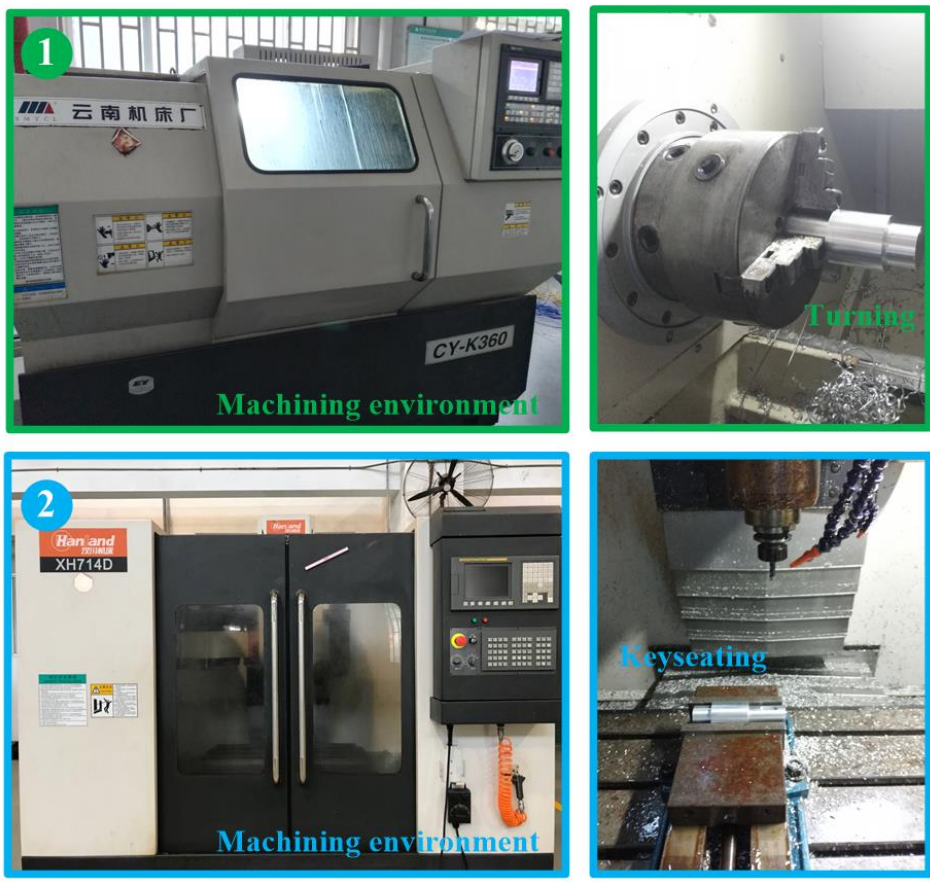

\begin{tabular}{|c|c|c|c|c|c|c|c|c|c|}
\hline \multicolumn{10}{|c|}{ Basic database for CY-K360 } \\
\hline \multicolumn{10}{|c|}{ Standby power } \\
\hline Machine tool & \multicolumn{2}{|c|}{ CY-K360 } & \multicolumn{2}{|c|}{$\begin{array}{l}\text { CNC machine tool } \\
\text { or not }\end{array}$} & Yes & & \multicolumn{2}{|c|}{ Standby power $p_{s b}(\mathrm{k})$} & 300 \\
\hline \multicolumn{10}{|c|}{ Starting energy consumption } \\
\hline Spindle speed $\boldsymbol{n}(\mathrm{rpm})$ & 300 & 500 & 700 & 900 & 1000 & 1100 & 1300 & 1500 & 1700 \\
\hline $\boldsymbol{E}_{\boldsymbol{s} \boldsymbol{t}}(\mathrm{kWh})$ & 0.0015 & 0.0015 & 0.002 & 0.002 & 0.002 & 0.002 & 0.002 & 0.002 & 0.003 \\
\hline Spindle speed $\boldsymbol{n}(\mathrm{rpm})$ & 1900 & & & & & & & & \\
\hline $\boldsymbol{E}_{\text {st }}(\mathrm{kWh})$ & 0.003 & & & & & & & & \\
\hline \multicolumn{10}{|c|}{ Idling power } \\
\hline Spindle speed $\boldsymbol{n}(\mathrm{rpm})$ & 300 & 500 & 700 & 900 & 1000 & 1100 & 1300 & 1500 & 1700 \\
\hline$p_{i d}(\mathrm{w})$ & 770 & 980 & 1090 & 1120 & 1160 & 1220 & 1400 & 1700 & 2450 \\
\hline Spindle speed $\boldsymbol{n}$ (rpm) & 1900 & & & & & & & & \\
\hline $\boldsymbol{p}_{\boldsymbol{i d}}(\mathrm{w})$ & 3000 & & & & & & & & \\
\hline \multicolumn{10}{|c|}{ Load loss coefficient $\boldsymbol{\alpha}$} \\
\hline \multicolumn{10}{|c|}{0.19} \\
\hline
\end{tabular}

The part is a coupling shaft, and the energy performance certification for the coupling shaft can be developed. The production processes for the coupling shaft merely involves the machining without other processes, and the energy is electricity energy. The data of the coupling shaft including energy data and information data can be acquired by the prediction method. The coupling shaft that is considered a function unit is shown in Fig. 12. The manufacturing equipment is machine tool (CY-K360 and XH714D). To acquire the electricity energy consumption for the coupling shaft, the basic database need to be established for the CY-K360 and XH714D. Due to the same method for establishing the basic database for the CY-K360 and

12 XH714D, this section only illustrates the establishment of the basic database for the CY-K360 13 in Table. 8. Besides, main machining parameters are shown in Table. 9, respectively. 
Tab. 9 Main machining parameters for the coupling shaft

\begin{tabular}{|c|c|c|c|c|c|c|c|}
\hline \multicolumn{8}{|c|}{ Machine tool: CY-K360 } \\
\hline \multirow[b]{2}{*}{ Step } & \multicolumn{3}{|c|}{ Content } & \multirow{2}{*}{$\begin{array}{c}\text { Spindle } \\
\text { speed } \\
(\mathrm{rpm})\end{array}$} & \multirow{2}{*}{$\begin{array}{c}\text { Feed } \\
(\mathrm{mm} / \mathrm{r})\end{array}$} & \multirow{2}{*}{$\begin{array}{l}\text { Depth of the } \\
\text { cut (mm) }\end{array}$} & \multirow{2}{*}{$\begin{array}{l}\text { Cutting } \\
\text { width } \\
\text { (mm) }\end{array}$} \\
\hline & Machining processes & $\begin{array}{l}\text { Cutting times } \\
\text { for machining }\end{array}$ & Other & & & & \\
\hline 1 & End of turning & Once & - & 1000 & 50 & 1.0 & - \\
\hline 2 & \multirow{8}{*}{$\begin{array}{l}\text { Turning } \\
\text { (Ø60mm) }\end{array}$} & \multirow{8}{*}{ Nine times } & \multirow{6}{*}{$\begin{array}{c}\text { Rough } \\
\text { Machining }\end{array}$} & 1000 & 100 & 1.5 & - \\
\hline 3 & & & & 1000 & 100 & 1.5 & - \\
\hline 4 & & & & 1000 & 100 & 1.5 & - \\
\hline 5 & & & & 1000 & 100 & 1.5 & - \\
\hline 6 & & & & 1000 & 100 & 1.5 & - \\
\hline 7 & & & & 1000 & 100 & 1.5 & - \\
\hline 8 & & & $\begin{array}{l}\text { Semi- } \\
\text { finishing }\end{array}$ & 1000 & 100 & 1.2 & - \\
\hline 9 & & & $\begin{array}{l}\text { Finish ma- } \\
\text { chining }\end{array}$ & 1000 & 100 & 0.3 & - \\
\hline & \multicolumn{6}{|c|}{ Turning around } & \\
\hline 10 & End of turning & Once & - & 1000 & 50 & 1.0 & - \\
\hline 11 & \multirow{2}{*}{$\begin{array}{l}\text { Turning } \\
\text { (Ø60mm) }\end{array}$} & \multirow{2}{*}{ Twice } & $\begin{array}{l}\text { Rough } \\
\text { machining }\end{array}$ & 1000 & 100 & 2.0 & - \\
\hline 12 & & & $\begin{array}{l}\text { Semi-fin- } \\
\text { ishing }\end{array}$ & 1000 & 100 & 0.7 & - \\
\hline 13 & \multirow{4}{*}{ Turning (Ø54.6mm) } & \multirow{4}{*}{ Four time } & \multirow{3}{*}{$\begin{array}{c}\text { Rough } \\
\text { machining }\end{array}$} & 1000 & 100 & 2.0 & - \\
\hline 14 & & & & 1000 & 100 & 2.0 & - \\
\hline 15 & & & & 1000 & 100 & 2.0 & - \\
\hline 16 & & & $\begin{array}{l}\text { Semi- } \\
\text { finishing }\end{array}$ & 1000 & 100 & 1.0 & - \\
\hline 17 & $\begin{array}{l}\text { Turning }(\varnothing 40.6 \mathrm{~mm}) \\
\text { and }(\varnothing 54.6 \mathrm{~mm})\end{array}$ & Once & $\begin{array}{l}\text { Finish ma- } \\
\text { chining }\end{array}$ & 1000 & 60 & 0.3 & - \\
\hline \multicolumn{8}{|c|}{ Machine tool: XH714D } \\
\hline 18 & \multirow{2}{*}{ keyseating } & \multirow{2}{*}{ Twice } & & 1000 & 50 & 5.0 & 10 \\
\hline 19 & & & & 1000 & 50 & 3.0 & 10 \\
\hline
\end{tabular}

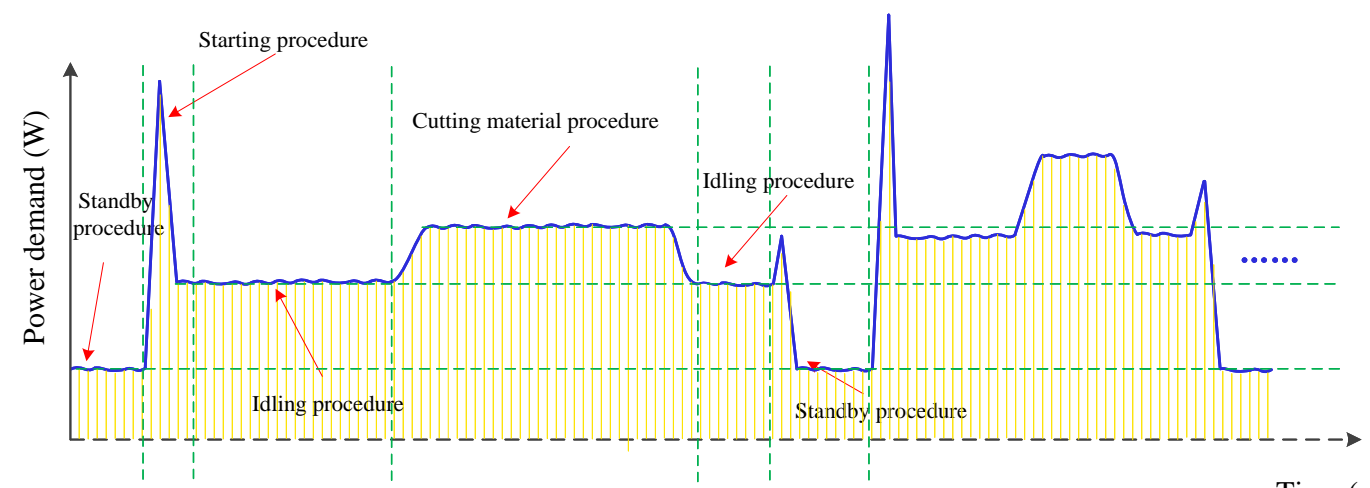

Fig. 13 A schematic diagram of a power profile for mechanical manufacturing (source: [90])

5 Meanwhile, the energy characteristics of the mechanical manufacturing process has been 6 analysed by authors as shown in Fig. 13. The mechanical manufacturing processes of the cou7 pling shaft are subdivided into the standby, starting, idling and cutting materials processes.

8 Thus, on basis of basic databases and machining parameters, the electricity energy consump-

9 tion of mechanical manufacturing processes for the coupling shaft is determined using Eqs.

10 (29)-(33) 


$$
E_{\text {Coupling shaft }}=\sum_{i=1}^{N_{s b}} E_{s b i}+\sum_{i=1}^{N_{s t}} E_{\text {sti }}+\sum_{i=1}^{N_{i d}} E_{\text {idi }}+\sum_{i=1}^{N c m} E_{c m i}
$$

Where, $E_{\text {Coupling shaft }}$ is energy consumption of one coupling shaft; $E_{s b}, E_{s t}, E_{i d}$ and $E_{c m}$ are the standby, starting, idling and cutting material energy consumption, respectively; $N_{s b}, N_{s t}, N_{i d}$ and $N_{c m}$ are the number of standby, starting, idling and cutting material processes, respectively.

Electricity energy consumption of the coupling shaft is calculated that is the prediction value as $E_{\text {Coupling shaft }}=0.555 \mathrm{kWh}$. To describe the energy performance and assess the influence of environment performance that is most closely related to climate change, this study set the $\mathrm{CO}_{2}$ emission density as a dependent variable as mentioned above. Therefore, the $\mathrm{CO}_{2}$ emission density for the unit coupling shaft is:

$$
C E_{\text {Coupling shaft }}\left(\mathrm{tCO}_{2}\right)
$$

$=($ The amount of electricity consumption $(\mathrm{kWh}))$

$\times\left(\right.$ Carbon dioxide emission factor for eletricity $\left.\left(\frac{\mathrm{tCO}_{2}}{\mathrm{MWh}}\right) \times\left(\frac{1}{10}\right)^{3}\right)$

$$
=0.555 \mathrm{kWh} \times 0.4705\left(\frac{\mathrm{tCO}_{2}}{\mathrm{MWh}}\right) \times\left(\frac{1}{10}\right)^{3}=0.261 \mathrm{gCO}_{2}
$$

The $\mathrm{CO}_{2}$ emission density for the unit coupling shaft $\left(0.261 \mathrm{gCO}_{2} /\right.$ unit coupling shaft $)$ can be determined as the energy benchmarking to perform the energy management and counting, and to control electricity energy consumption, especially in monitoring the effects to climate change. However, for the coupling shaft, the current electricity energy consumption (or $\mathrm{CO}_{2}$ emission density) is initial benchmarking, which aims at promoting a majority of the coupling shaft to meet it. But, the electricity energy consumption $0.555 \mathrm{kWh}$ (or $\mathrm{CO}_{2}$ emission density $0.261 \mathrm{gCO}_{2} /$ unit coupling shaft) can be reduced by some effective measures or optimization method, etc. For the case, by the optimization of mechanical manufacturing process and machining parameters using advanced machine tools and excellent parameters, the overall minimum electricity energy for the unit coupling shaft can be determined as $0.402 \mathrm{kWh}$, the detailed process is neglected because of space limit. Therefore, the overall minimum energy performance index for the unit coupling shaft $\mathrm{EPI}_{\mathrm{Min}}=0.189 \mathrm{gCO}_{2} /$ unit coupling shaft. Besides, for the coupling shaft, using the Eqs. (19)- (26). The number of the evaluation grade $N$ is five, and the energy rating are $\alpha=0.276, \Delta=0.092, \alpha_{1} \in(0,72.4), \alpha_{2} \in[72.4,81.6), \alpha_{3} \in$ $[81.6,90.8), \alpha_{4} \in[90.8,100)$ and $\alpha_{5} \in[100,+\infty)$. On this basis, combining the energy labelling in section 6.4 , the energy performance certification for the coupling shaft can be developed as shown in Fig. 14. 
Energy Performance Certification

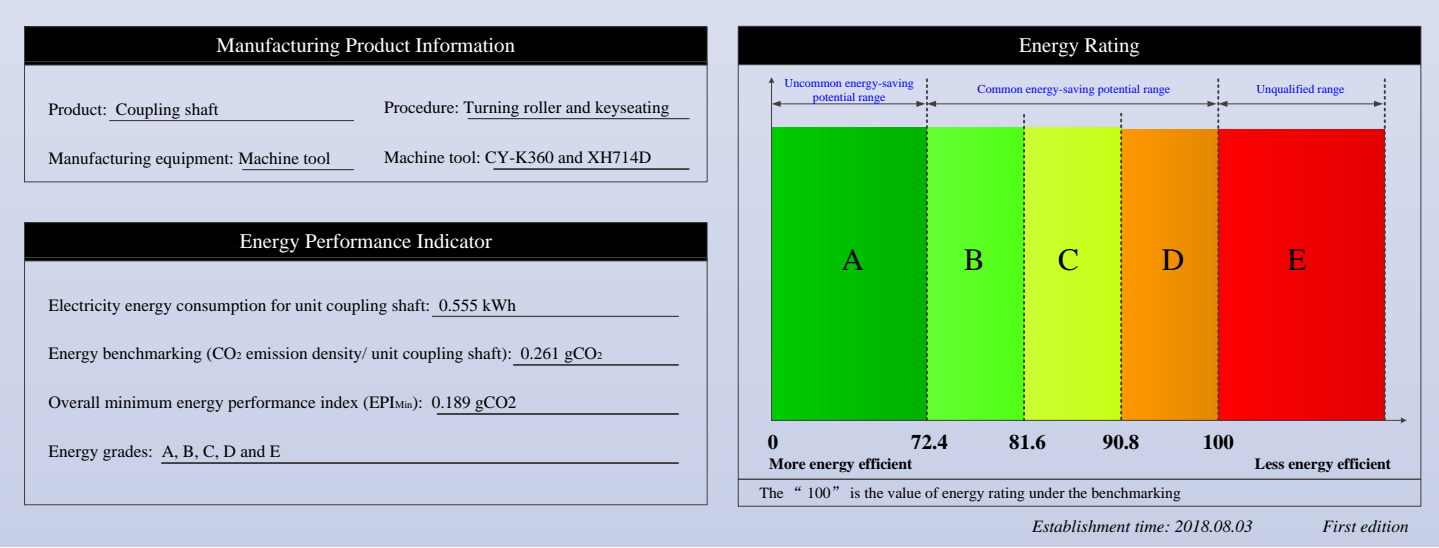

Fig.14 The energy performance certification for the coupling shaft

The energy performance certification is important to evaluate energy performance and promote energy efficiency. From the perspective of mechanical manufacturing, electricity energy consumption and $\mathrm{CO}_{2}$ emission density of one coupling shaft could easily be grasped by operators. The energy rating and grades could be analysed in real production by a comparison with energy rating system to guide operators to avoid unreasonable machining parameters and to select more reasonable machining plans and efficient process parameters. From the perspective of energy management, energy managers can count the overall energy level and $\mathrm{CO}_{2}$ emission density of the coupling shaft and workshop via energy performance certification.

11 The energy performance certification also benefits for conducting energy audits, a collection

12 of energy statistics, energy-efficiency analysis, aiding the decision-making processes of energy 13 managers. From the perspective of government, energy performance certification is as an ef14 fective tool for designing relevant energy policies and standards towards energy saving and 15 low carbon. For example, when $\mathrm{CO}_{2}$ emission density of one mechanical manufacturing system 16 exceeds the energy grade for energy rating, the firm could be subject to financial and admin17 istrative penalties in accordance with the extent they breach the grade. Incentive schemes may 18 be implemented for firms that satisfy energy benchmarks and grades. In conclusion, energy 19 performance certification in the mechanical manufacturing is significant measure for realizing energy-efficient production and $\mathrm{CO}_{2}$ emission mitigation.

\section{Conclusions}

The mechanical manufacturing industry as one of the important pillars of the national economy consumes huge amounts of energy and brings a lot of $\mathrm{CO}_{2}$ emissions resulting in huge environmental burden. The energy performance certification is an effective tool to systematically manage the energy consumption and improve energy performance, as well as further mitigate $\mathrm{CO}_{2}$ emissions. This paper mainly focused on analysis of energy benchmarking, 
1 rating, mining and labelling within the framework of energy performance certification in me-

2 chanical manufacturing industry to better identify the potentials and applicability of different energy performance certification.

First, the existing energy measures in the mechanical manufacturing including the energy measurement, monitoring, modelling, optimization and other strategies, were analysed,

6 which contributes to understanding the method to promote the energy performance. The con7 cept of energy performance certification was introduced, and the research progress on the energy performance certification and research gaps in the mechanical manufacturing industry were systematically analysed. On this basis, the objective and framework of this study was illustrated.

Analysis of the mechanical manufacturing process and energy consumption, as the significant basis of analysing energy characteristics, were performed. Energy data is important basis of developing the manufacturing energy certification, and methods for acquiring the data were summarized and analysed from the perspectives of variable definition and data collection and unification.

Second, on the basis of analysing the energy performance and requirements for mechanical manufacturing industry, definition and connotation of energy performance certification of mechanical manufacturing were illustrated. The energy performance certification contains overall energy performance index (EPI), overall minimum energy performance index (EPI $\mathrm{Min}_{\text {) }}$, energy rating, a label based in the A-E bands and manufacturing product information (MPI). According to definition and scope of energy performance certification, it was a representation of the integrated information, and it comprised various types including the energy benchmarking, rating, and labelling. This paper attempted to define and clarify concepts of energy benchmarking, rating, mining and labelling in the context of manufacturing energy classification to develop the certification.

Besides, some key issues for energy performance certification (i.e. assessing energy efficiency of mechanical manufacturing, acquiring the energy data in mechanical manufacturing, comparing the energy performance of mechanical manufacturing) were analysed. To systematically discuss the energy performance certification, this study not only illustrated development process for energy performance certification but also demonstrated and analysed the practicability for a real production process. The review and analysis on the energy performance certification was an important cornerstone for promoting the development of energy

33 performance certification in mechanical manufacturing industry. Meanwhile, this study could

34 play an important role in strengthening energy management and monitoring, and promoting energy performance in mechanical manufacturing industry. 


\section{Acknowledgments}

3 This work was supported by Fundamental Research Funds for the Central Universities

4 (SWU118068), the National Natural Science Foundation of China (Grant No. 51875480 and

5 51805479) and Humanities and Social Science Research of Ministry of Education 6 (No.17YJC630082).

\section{$7 \quad$ References}


[1] Cai W, Liu C, Zhang C, et al. Developing the ecological compensation criterion of industrial solid waste based on emergy for sustainable development. Energy, 2018, 157:940-948.

[2]Ma M, Cai W, Cai W. Carbon abatement in China's commercial building sector: A bottom-up measurement model based on Kaya-LMDI methods. Energy, 2018, 165: 350-368.

[3] Tiba, S, Anis O. Literature survey on the relationships between energy, environment and economic growth. Renewable and Sustainable Energy Reviews, 2017, 69: 1129-1146.

[4] Ma M, Cai W, Wu Y. China act on the energy efficiency of civil buildings (2008): a decade review. Science of the Total Environment, 2019, 31 (1), 1-12.

[5] Xu L, Wang C, Zhao J. Decision and coordination in the dual-channel supply chain considering cap-andtrade regulation. Journal of Cleaner Production, 2018. 197: 551-561.

[6] IEA, "IEA Atlas of Energy", IEA World Energy Statistics and Balances (database), www.energyatlas.iea.org/\#!/tellmap/1002896040/2

[7]Ma M, Cai W. Do commercial building sector-derived carbon emissions decouple from the economic growth in Tertiary Industry? A case study of four municipalities in China. Science of The Total Environment, 2019, 650: 822-834.

[8] Park C-W, Kwon K-S, Kim W-B, Min B-K, Park S-J, Sung I-H, et al. Energy consumption reduction technology in manufacturing - a selective review of policies, standards, and research. Int J Precis Eng Manuf 2009; 10:151-73.

[9] Andrea Trianni, Enrico Cagno, Stefano Farné. Barriers, drivers and decision-making process for industrial energy efficiency: A broad study among manufacturing small and medium-sized enterprises. Applied Energy.2016; 162:1537-1551.

[10] Abdelaziz E.A, Saidur R, Mekhilef S. A review on energy saving strategies in industrial sector. Renewable and Sustainable Energy Reviews 2011; 15 (1):150-168.

[11] Xu L, Wang C. Sustainable manufacturing in a closed-loop supply chain considering emission reduction and remanufacturing. Resources, Conservation and Recycling, 2018, 131: 297-304.

[12] Jiang Z, Jiang Y, Wang Y, et al. A hybrid approach of rough set and case-based reasoning to remanufacturing process planning. Journal of Intelligent Manufacturing, 2019, 30:19-32

[13] Liu Fei, Wang Qiulian, Liu Gaojun. Content architecture and future trends of energy efficiency research on machining systems. Journal of Mechanical Engineering 2013; 49 (19): 87-94.

[14] Gutowski T G, Branham M S, Dahmus J B. Thermodynamic Analysis of Resources Used in Manufacturing Processes. Environmental Science and Technology 2009; 43(5):1584-1590.

[15] Abdelaziz EA, Saidur R, Mekhilef S. A review on energy saving strategies inindustrial sector.Renew Sustain Energy Rev 2011;15:150-68.

[16] Jiang Z, Wang H, Zhang H, et al. Value recovery options portfolio optimization for remanufacturing end of life product. Journal of Cleaner Production, 2019, 210: 419-431.

[17] Wang H, Jiang Z, Zhang H, et al. An integrated MCDM approach considering demands-matching for reverse logistics. Journal of Cleaner Production, 2019, 208: 199-210.

[18] Tanaka K. Review of policies and measures for energy efficiency in industry sector. Energy Policy 2011; 39:6532-50.

[19] Bogdanski G, Spiering T, Li W, et al. Energy monitoring in manufacturing companies - generating energy awareness through feedback, in: D.A. Dornfeld, B.S. Linke (Eds.), Leveraging Technology for a Sustainable World, Springer, Berlin/Heidelberg,2012, pp.539-544.

[20] S. Kara, G.Bogdanski, W.Li, Electricity metering and monitoring in manufacturing systems, in:J. Hesselbach, C.Herrmann(Eds.), Globalized Solutions for Sustainability in Manufacturing:Proceedings of the 18th CIRP International Conference on Life Cycle Engineering, Springer Verlag, Berlin/Heidelberg, 2011,pp.1-10. [21]Verein Deutscher Ingenieure VDI, Energiemanagement - Begriffe, No. 4602, Beuth Verlag, Düsseldorf,2007.

[22] Hu S, Liu F, He Y, et al. An on-line approach for energy efficiency monitoring of machine tools. Journal of cleaner production, 2012, 27: 133-140.

[23]Vijayaraghavan A, Dornfeld D. Automated energy monitoring of machine tools. CIRP Annals-Manufacturing Technology, 2010, 59(1): 21-24. 
[24]Behrendt T, Zein A, Min S. Development of an energy consumption monitoring procedure for machine tools. CIRP Annals-Manufacturing Technology, 2012, 61(1): 43-46.

[25]Gutowski, T., Dahmus, J., Thiriez, A. Electrical energy requirements for manufacturing processes. In: Proceedings of 13th CIRP International Conference on Life Cycle Engineering. Leuven, Belgium, 2006 pp. 5-11.

[26]Gutowski, T., Branham, M., Dahmus, J., Jones, A., Thiriez, A. Thermodynamic analysis of resources used in manufacturing processes. Environ. Sci. Technol. 2009,43(5), 1584-1590.

[27]Kara, S., Li, W., 2011a. Unit process energy consumption models for material processes. CIRP Ann. Manuf. Technol. 61 (1), 37-40.

[28] Hu L, Peng C, Evans S, et al. Minimising the machining energy consumption of a machine tool by sequencing the features of a part. Energy, 2017,121:292-305.

[29] Hu L, Tang R, Liu Y, et al. Optimising the machining time, deviation and energy consumption through a multi-objective feature sequencing approach. Energy Conversion and Management, 2018, 160: 126-140.

[30] Jia S, Yuan Q, Cai W, et al. Energy modeling method of machine-operator system for sustainable machining. Energy Conversion and Management, 2018, 172: 265-276.

[31] Jia S, Yuan Q, Lv J, et al. Therblig-embedded value stream mapping method for lean energy machining. Energy, 2017, 138: 1081-1098.

[32] Lv J, Tang R, Tang W, et al. An investigation into methods for predicting material removal energy consumption in turning. Journal of Cleaner Production, 2018, 193: 128-139.

[33] Lv J, Peng T, Tang R. Energy modeling and a method for reducing energy loss due to cutting load during machining operations. 2018, DOI:10.1177/0954405418769922.

[34] Yoon H S, Lee J Y, Kim M S, et al. Empirical power-consumption model for material removal in three-axis milling. Journal of Cleaner Production, 2014, 78: 54-62.

[35] Yoon, H.S., Moon, J.S., Pham, M.Q., Lee, G.B., Ahn, S.H., 2013. Control of machining parameters for energy and cost savings in micro-scale drilling of PCBs. J. Clean. Prod. 54, 41-48.

[36]Mohammed, S., Martin, P., Hakan, H., Julfikar, H. Measurement of specific cutting energy for evaluating the efficiency of bandsawing different workpiece materials. Int. J. Mach. Tools Manuf. 2009,49 (12-13), 958-965.

[37] Guo, Y.S., Loenders, J., Duflou, J., Lauwers, B. Optimization of energy consumption and surface quality in finish turning. Procedia CIRP, 2012,1 (1), 512-517.

[38]Li W, Zein A, Kara S, et al. An investigation into fixed energy consumption of machine tools. Glob. Solut. Sustain. Manuf.-Energy Effic. Mach. Tools 2011:268-273.

[39]Cai W, Liu F, Hu S. An analytical investigation on energy efficiency of high-speed dry-cutting CNC hobbing machines. International Journal of Sustainable Engineering, 2017: 1-8.

[40]May G, Stahl B, Taisch M, et al. Energy management in manufacturing: From literature review to a conceptual framework. Journal of Cleaner Production, 2017, 167: 1464-1489.

[41]Liu F, Zhou X N, Cai W. The complexity and strategy for establishing product energy consumption allowance in discrete manufacturing industry, Journal of Mechanical Engineering,2015,51(19):138-145 [In Chinese]

[42]Bernard J T, Côté B. The measurement of the energy intensity of manufacturing industries: a principal components analysis. Energy Policy, 2005, 33(2): 221-233.

[43]Duflou J R, Sutherland J W, Dornfeld D, et al. Towards energy and resource efficient manufacturing: A processes and systems approach. CIRP Annals-Manufacturing Technology, 2012, 61(2): 587-609.

[44]Wang Q, Liu F, Li C. An integrated method for assessing the energy efficiency of machining workshop. Journal of Cleaner Production, 2013, 52: 122-133.

[45]Schudeleit T, Züst S, Wegener K. Methods for evaluation of energy efficiency of machine tools. Energy, 2015, 93: 1964-1970.

[46]Schudeleit T, Züst S, Weiss L, et al. The Total Energy Efficiency Index for machine tools. Energy, 2016, 102: 682-693.

[47]Liu C, Cai W, Dinolov 0, et al. Emergy based sustainability evaluation of remanufacturing machining systems. Energy, 2018, 150: 670-680.

[48]Diaz N, Helu M, Jarvis A, et al. Strategies for minimum energy operation for precision machining. Laboratory for Manufacturing and Sustainability, 2009.

[49] Li L, Li C, Tang Y, et al. Influence factors and operational strategies for energy efficiency improvement of CNC machining. Journal of Cleaner Production, 2017, 161: 220-238. 
[50] Aramcharoen A, Mativenga P T. Critical factors in energy demand modelling for CNC milling and impact of toolpath strategy. Journal of Cleaner Production, 2014, 78: 63-74.

[51]Yoon H S, Kim E S, Kim M S, et al. Towards greener machine tools-A review on energy saving strategies and technologies. Renewable and Sustainable Energy Reviews, 2015, 48: 870-891.

[52]Kumar, Rajesh, and Arun Agarwala. Energy certificates REC and PAT sustenance to energy model for India. Renewable and Sustainable Energy Reviews,2013, 21: 315-323.

[53]Afshari, Afshin, and Luiz Friedrich. A proposal to introduce tradable energy savings certificates in the emirate of Abu Dhabi. Renewable and Sustainable Energy Reviews,2016, 55: 1342-1351.

[54]Wędzik, Andrzej, Tomasz Siewierski, and Michał Szypowski. Green certificates market in Poland-The sources of crisis. Renewable and Sustainable Energy Reviews,2017, 75: 490-503.

[55]Koo, C, et al. Development of a new energy efficiency rating system for existing residential buildings. Energy Policy,2014, 68: 218-231.

[56]Jeong, Jaewook, Hong J, Ji C, et al. Improvements of the operational rating system for existing residential buildings. Applied energy,2017, 193: 112-124.

[57]Andaloro APF, Salomone R, Ioppolo G, Andaloro L. Energy certification of buildings: a comparative analysis of progress towards implementation in European countries. Energy Policy 2010; 38:5840-66.

[58]Intelligent Energy Europe Programme (IEEP). Implementing the Energy Performance of Buildings Directive (EPBD): Featuring country reports 2010. IEEP: Brussels; 2011.

[59]Koo C, Hong T. Development of a dynamic operational rating system in energy performance certificates for existing buildings: geostatistical approach and data-mining technique. Applied energy, 2015, 154: 254270 .

[60]Sunikka M. The Energy Performance of Buildings Directive (EPBD): Improving the energy efficiency of the existing housing stock. Delft: Delft University of Technology (DUT); 2005.

[61]Herrando M, Cambra D, Navarro M, et al. Energy Performance Certification of Faculty Buildings in Spain: The gap between estimated and real energy consumption. Energy Conversion and Management, 2016, 125: 141-153.

[62]J Jeong J, Hong T, Ji C, et al. Improvements of the operational rating system for existing residential buildings. Applied energy, 2017, 193: 112-124.

[63]Rastogi A, Choi J K, Hong T, et al. Impact of different LEED versions for green building certification and energy efficiency rating system: A Multifamily Midrise case study. Applied Energy, 2017, 205: 732-740.

[64] Pérez-Lombard L, Ortiz J, González R, et al. A review of benchmarking, rating and labelling concepts within the framework of building energy certification schemes. Energy and Buildings, 2009, 41(3): 272-278.

[65] Andaloro A P F, Salomone R, Ioppolo G, et al. Energy certification of buildings: A comparative analysis of progress towards implementation in European countries. Energy Policy, 2010, 38(10): 5840-5866.

[66] Casals X G. Analysis of building energy regulation and certification in Europe: Their role, limitations and differences. Energy and buildings, 2006, 38(5): 381-392.

[67] Buratti C, Barbanera M, Palladino D. An original tool for checking energy performance and certification of buildings by means of Artificial Neural Networks. Applied Energy, 2014, 120: 125-132.

[68] Park D J, Yu K H, Yoon Y S, et al. Analysis of a building energy efficiency certification system in Korea. Sustainability, 2015, 7(12): 16086-16107.

[69] Lewandowski I, Faaij A P C. Steps towards the development of a certification system for sustainable bioenergy trade. Biomass and Bioenergy, 2006, 30(2): 83-104.

[70] Rikhtegar F. Energy benchmarking: a method incorporating energy optimization and its viability is exemplified in a petrochemical application. Chemical Engineering, 2011, 118(12): 32-36.

[71] Rahdari A H. Developing a fuzzy corporate performance rating system: a petrochemical industry case study. Journal of Cleaner Production, 2016, 131: 421-434.

[72] Koitmets K, Reinsalu E, Valgma I. Precision of oil shale energy rating and oil shale resources. Oil Shale, 2003, 20(1): 15-24.

[73] Worrell E, Price L. An integrated benchmarking and energy savings tool for the iron and steel industry. International journal of green energy, 2006, 3(2): 117-126.

[74] Zeng X. Cement grinding technologies and energy benchmarking//Proceedings of the 2009 China Cement Grinding Technology Forum, Nanjng, Jiangsu, China, April 18th.< http://www. ccement. com/news/2009/4-18 C. 2009, 12177667. 
[75] Skeaff J, Adams W J, Rodriguez P, et al. Advances in metals classification under the United Nations globally harmonized system of classification and labeling. Integrated environmental assessment and management, 2011, 7(4): 559-576.

[76] Wang N, Wen Z, Liu M, et al. Constructing an energy efficiency benchmarking system for coal production. Applied Energy, 2016, 169: 301-308.

[77] Laurijssen J, Faaij A, Worrell E. Benchmarking energy use in the paper industry: a benchmarking study on process unit level. Energy efficiency, 2013, 6(1): 49-63.

[78] Papaefthimiou S, Syrrakou E, Yianoulis P. An alternative approach for the energy and environmental rating of advanced glazing: An electrochromic window case study. Energy and Buildings, 2009, 41(1): 17-26.

[79] Krampe J. Energy benchmarking of South Australian WWTPs. Water Science and Technology, 2013, 67(9): 2059-2066.

[80] Ortega E, Anami M, Diniz G. Certification of food products using emergy analysis//Proceedings of III International Workshop Advances in Energy Studies. 2002: 227-237.

[81] Ming C, Lixin Z, Yishui T, et al. Analysis and evaluation on energy utilization of main crop straw resources in China. Transactions of the Chinese Society of Agricultural Engineering, 2008, 2008(12).

[82] Glatt S, Cox D, Nimbalkar S U, et al. Industrial Energy Training and Certification. Plant Engineering, 2017, 2017(November).

[83] Mahlia T M I, Masjuki H H, Taha F M, et al. Energy labeling for electric fans in Malaysia. Energy policy, 2005, 33(1): 63-68.

[84] Cai W, Liu F, Dinolov O, et al. Energy benchmarking rules in machining systems. Energy, 2018, 142: 258263.

[85] Cai W, Liu F, Zhang H, et al. Development of dynamic energy benchmark for mass production in machining systems for energy management and energy-efficiency improvement. Applied Energy, 2017, 202: 715-725.

[86] Ke J, Price L, McNeil M, et al. Analysis and practices of energy benchmarking for industry from the perspective of systems engineering. Energy, 2013, 54: 32-44.

[87] Kenny R P, Friesen G, Chianese D, et al. Energy rating of PV modules: comparison of methods and approach//Photovoltaic Energy Conversion, 2003. Proceedings of 3rd World Conference on. IEEE, 2003, 2 : 2015-2018.

[88] Zhou H, Bukenya J O. Information inefficiency and willingness-to-pay for energy-efficient technology: A stated preference approach for China Energy Label. Energy Policy, 2016, 91: 12-21.

[89]Cai W, Liu F, Zhou X N. Fine energy consumption allowance of workpieces in the mechanical manufacturing industry. Energy 2016; 114: 622-623.

[90] Cai W, Liu F Xie J, et al. An energy management approach for the mechanical manufacturing industry through developing a multi-objective energy benchmark. Energy Conversion and Management, 2017, 132: 361-371.

[91] Council Directive 93/76/CEE of 13 September 1993 to limit carbon dioxideemissions by improving energy efficiency (SAVE).

[92] Olaussen J, Oust A, Solstad J. Energy performance certificates-Informing the informed or the indifferent?, Energy Policy,2017,111: 246-254.

[93] Dan Song, Jin Yang, Bin Chen. Life-cycle environmental impact analysis of a typical cement production chain. Applied Energy 2016;64: 916-923.

[94] Zhou X, Liu F, Cai W. An energy-consumption model for establishing energy-consumption allowance of a workpiece in a machining system. Journal of Cleaner Production 2016; 135: 1580-1590.

[95] Cai W, Liu F, Xie J, et al. A tool for assessing the energy demand and efficiency of machining systems: energy benchmarking. Energy, 2017, 138: 332-347.

[96] Řezáč J, Jurečka P, Riley K E, et al. Quantum chemical benchmark energy and geometry database for molecular clusters and complex molecular systems (www. begdb. com): a user's manual and examples. Collection of Czechoslovak Chemical Communications 2008; 73(10): 1261-1270.

[97] Sardeshpande V, Gaitonde U N, Banerjee R. Model based energy benchmarking for glass furnace. Energy Conversion and Management 2007; 48(10): 2718-2738.

[98] Saleh F K, Teodoriu C. The mechanism of mixing and mixing energy for oil and gas wells cement slurries: A literature review and benchmarking of the findings. Journal of Natural Gas Science and Engineering, 2016.

[99] Nadolski S, Klein B, Gong D, et al. Development and application of an energy benchmarking model for 
mineral comminution. SAG2015, Vancouver, 2015.

[100] Sahoo L K, Bandyopadhyay S, Banerjee R. Benchmarking energy consumption for dump trucks in mines. Applied Energy 2014; 113: 1382-1396.

[101] Ballantyne G R, Powell M S. Benchmarking comminution energy consumption for the processing of coper and gold ores. Minerals Engineering 2014; 65: 109-114.

[102]Laurijssen J, Faaij A, Worrell E. Benchmarking energy use in the paper industry: a benchmarking study on process unit level. Energy efficiency 2013; 6(1): 49-63.

[103]Zhang Y, Hong M, Li J, et al. Benchmarking Analysis of Energy Efficiency Indicators in Paper Mill. BioResources 2016; 11(4): 9723-9740.

[104] Mateos-Espejel E, Savulescu L, Maréchal F, et al. Base case process development for energy efficiency improvement, application to a Kraft pulping mill. Part II: benchmarking analysis. Chemical Engineering Research and Design 2011; 89(6): 729-741.

[105] Jonasson M. Energy benchmark for wastewater treatment processes-a comparison between Sweden and Austria. TEIE-5247, IEA, 2007.

[106] Phylipsen D, Blok K, Worrell E, et al. Benchmarking the energy efficiency of Dutch industry: an assessment of the expected effect on energy consumption and CO2 emissions. Energy policy, 2002, 30(8): 663-679. [107] Prakash B, Singh R P. Energy benchmarking of warehouses for frozen foods. Food Manufacturing Efficiency 2008, 1(3), 9.

[108] Chauhan N S, Mohapatra P K J, Pandey K P. Improving energy productivity in paddy production through benchmarking - an application of data envelopment analysis. Energy Conversion and Management 2006; 47(9): 1063-1085.

[109]Saygin D, Worrell E, Patel M K, et al. Benchmarking the energy use of energy-intensive industries in industrialized and in developing countries. Energy, 2011, 36(11): 6661-6673.

[110] Chan D Y L, Yang K H, Hsu C H, et al. Current situation of energy conservation in high energy-consuming industries in Taiwan. Energy policy, 2007, 35(1): 202-209.

[111]ElMaraghy H A, Youssef A M A, Marzouk A M, et al. Energy use analysis and local benchmarking of manufacturing lines. Journal of Cleaner Production, 2017, 163: 36-48.

[112] Jia S, Yuan Q, Cai W, et al. Energy modeling method of machine-operator system for sustainable machining. Energy Conversion and Management, 2018, 172: 265-276.

[113] Real Decreto 47/2007, de 19 de enero, por el que se aprueba el Procedimiento ba' sico para la certificacio'n de eficiencia energe' tica de edificios de nueva construccio' n, 2007. 